\title{
Equilibrium vs Ground-State Planarity of the CONH Linkage
}

\author{
Jean Demaison,*,† Attila G. Császár,*** Isabelle Kleiner, ${ }^{\S}$ and Harald Møllendal ${ }^{\|}$ \\ Laboratoire de Physique des Lasers, Atomes et Molécules, UMR CNRS 8523, Université de Lille I, \\ 59655 Villeneuve d'Ascq Cedex, France, Laboratory of Molecular Spectroscopy, Institute of Chemistry, \\ Eötvös University, P.O. Box 32, H-1518 Budapest 112, Hungary, Laboratoire Interuniversitaire des Systèmes \\ Atmosphériques, Université de Paris XII et Paris VII and CNRS, 61, avenue du Général De Gaulle, \\ 94010 Créteil Cedex, France, and Department of Chemistry, University of Oslo, P.O. Box 1033 Blindern, \\ N-0315 Oslo, Norway
}

Received: November 5, 2006; In Final Form: January 22, 2007

\begin{abstract}
Planarity of the $\mathrm{XC}(=)$ NHY linkage has been investigated in unprecedented detail in a number of relatively simple compounds, including formamide $(\mathrm{X}=\mathrm{Y}=\mathrm{H})$, acetamide $\left(\mathrm{X}=\mathrm{CH}_{3}, \mathrm{Y}=\mathrm{H}\right)$, urea $\left(\mathrm{X}=\mathrm{NH}_{2}, \mathrm{Y}\right.$ $=\mathrm{H})$, carbamic acid $(\mathrm{X}=\mathrm{OH}, \mathrm{Y}=\mathrm{H})$, and methyl carbamate $\left(\mathrm{X}=\mathrm{OCH}_{3}, \mathrm{Y}=\mathrm{H}\right)$. Reliable estimates of the equilibrium structures of formamide, cyanamide, acetamide, urea, carbamic acid, methylamine, dimethyl ether, and methyl carbamate are derived, mostly for the first time. It is shown that formamide, considered prototypical for the amide linkage, is not typical as it has a planar equilibrium amide linkage corresponding to a single-minimum inversion potential around $\mathrm{N}$. In contrast, several molecules containing the $\mathrm{CONH}$ linkage seem to have a pyramidalized nitrogen at equilibrium and a double-minimum inversion potential with a very small inversion barrier allowing for an effectively planar ground-state structure. Observables of rotational spectroscopy, including ground-state inertial defects, quadrupole coupling and centrifugal distortion constants, and dipole moment components, as well as equilibrium $\mathrm{C}=\mathrm{O}$ and $\mathrm{C}-\mathrm{N}$ bond lengths are reviewed in their ability to indicate the planarity of the effective and possibly the equilibrium structures.
\end{abstract}

\section{Introduction}

The $\mathrm{XC}(=\mathrm{O}) \mathrm{NHY}$ linkage, under the assumption $\mathrm{Y}=\mathrm{H}$ called the amide linkage, or referred to as the peptide linkage, is genrally assumed to have a planar structure. ${ }^{1}$ This is usually attributed to the contribution of a resonance structure $\mathrm{O}^{-}-\mathrm{CX}=\mathrm{N}^{+} \mathrm{HY}$, which induces a partial double bond character of the $\mathrm{C}-\mathrm{N}$ bond. ${ }^{1}$ Wiberg and co-workers ${ }^{2}$ proposed that the resonance structure $\mathrm{O}^{-} \mathrm{C}^{+} \mathrm{X}-$ :NHY is another major contributor to the overall $\pi$-electron charge distribution in amides. Whatever is the most pedagogical interpretation of the assumed planarity of the $\mathrm{XC}(=\mathrm{O}) \mathrm{NHY}$ linkage, contributions of resonance structures can be changed by interactions with the environment of the linkage represented by the substituents $\mathrm{X}$ and $\mathrm{Y}$, which may result in deviations from planarity. ${ }^{2-5}$ Furthermore, it is shown in this study that many of the molecules containing the $\mathrm{XC}(=\mathrm{O}) \mathrm{NHY}$ linkage are not planar at equilibrium. Therefore, explaining their planar ground-state structure by arguments based on equilibrium properties is somewhat controversial.

As to planarity, the simple molecules containing the $\mathrm{C}(=\mathrm{O}) \mathrm{NH}$ linkage considered in this study can be divided into three groups: (i) all of the atoms of the molecule lie in a plane, i.e., the point-group symmetry of the molecule is at least $C_{s}$; (ii) all of the atoms of the molecule lie in a plane except pairs of hydrogen atoms which are situated symmetrically about the plane of symmetry, i.e., the point-group symmetry of the molecule is $C_{s}$; and (iii) molecules which do not have a plane of symmetry. Rotational spectroscopy and high-level quantum

* To whom correspondence should be addressed. E-mail: Jean.Demaison@univ-lille1.fr. E-mail: csaszar@chem.elte.hu.

†Université de Lille I.

Eötvös University.

§ Université de Paris XII.

"University of Oslo. chemical calculations are the most suitable methods available today to determine which of these categories a molecule belongs to. Furthermore, since rotational transitions correspond to effective structures while electronic structure calculations in their simplest form determine equilibrium structures, in certain cases the question whether the molecule has a plane of symmetry or not at its equilibrium or vibrationally averaged state arises naturally.

The molecule considered prototypical for the amide linkage is formamide, $\mathrm{HCONH}_{2}$, i.e., $\mathrm{X}=\mathrm{Y}=\mathrm{H}$. The planarity of the equilibrium structure of formamide, corresponding to a singleminimum inversion potential, has been the subject of numerous spectroscopic and quantum chemical investigations. The rich history is reviewed nicely, for example, in ref 3 . The interested reader is referred to this paper and the original publications for details. The large number of investigations reflects the subtlety of the issues related to planarity. Although the most recent computational $^{3,5}$ and experimental (empirical) ${ }^{6}$ studies proved beyond reasonable doubt the $C_{s}$ point-group symmetry of the Born-Oppenheimer equilibrium structure, $r_{\mathrm{e}}^{\mathrm{BO}}$, of formamide, an $r_{\mathrm{e}}^{\mathrm{BO}}$ consistent with all available experimental and quantum chemical information has not been derived. An aim of the present study thus has been to derive a representation of the equilibrium structure of formamide. The resulting $r(\mathrm{C}-\mathrm{N})$ and $r(\mathrm{C}=\mathrm{O})$ bond lengths, central to resonance models explaining the planarity of the amide linkage, are given special attention, not only in formamide but also in a number of related compounds, most containing the $\mathrm{XC}(=\mathrm{O}) \mathrm{NHY}$ linkage, in order to provide dependable results for meaningful structural comparisons.

The question of the planarity of the CONH linkage is considerably more interesting in those molecules that are suspected not to have a single-minimum inversion potential 


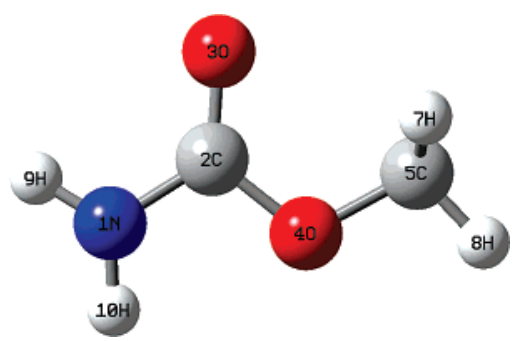

Figure 1. Conformation and atomic numbering of syn-methyl carbamate.

around $\mathrm{N}$ but contain a pyramidalized nitrogen at equilibrium. In these cases, the inversion barrier might be so small that, although the equilibrium structure is nonplanar, the effective structure determining the spectroscopic observables is in fact planar. A prototypical molecule which has been suspected to show such behavior is methyl carbamate $\left(\mathrm{MC}, \mathrm{H}_{2} \mathrm{NC}(\mathrm{O}) \mathrm{OCH}_{3}\right.$, $\mathrm{X}=\mathrm{OCH}_{3}$ and $\mathrm{Y}=\mathrm{H}$, see Figure 1). To substantiate claims about planar vs nonplanar $\mathrm{CONH}$ linkages, measurements in the microwave regions and fitting of effective Hamiltonians have been performed on MC as part of this study. Furthermore, electronic structure calculations, pushed to the technical limits, have been executed for this molecule, as well. This study establishes that the equilibrium structure of MC has a nonplanar heavy-atom skeleton.

The equilibrium structures of further molecules, cyanamide $\left(\mathrm{NH}_{2} \mathrm{CN}\right)$, acetamide $\left(\mathrm{X}=\mathrm{CH}_{3}, \mathrm{Y}=\mathrm{H}\right)$, urea $\left(\mathrm{X}=\mathrm{NH}_{2}, \mathrm{Y}=\right.$ $\mathrm{H}$ ), and carbamic acid ( $\mathrm{CA}, \mathrm{X}=\mathrm{OH}, \mathrm{Y}=\mathrm{H}$ ), have been investigated to gain further insight into the planarity of the amide linkage. The main question here is whether the single-minimum Born-Oppenheimer equilibrium potential of formamide or the double-minimum curve of MC should be considered typical for the amide linkage. Similarly to MC, cyanamide, acetamide, urea, and carbamic acid all have a pyramidalized equilibrium amide linkage, as confirmed by high-level electronic structure calculations of this study consistent with the available experimental information. Note that carbamic acid was also studied because MC is its ester and because the nonplanarity of some peptide linkages was suggested to be related to the low potential barrier of the methyl group they contained. ${ }^{7}$

Since most of the new purely experimental information presented in this paper is related to $\mathrm{MC}$, it is appropriate to point out the importance of the experimental and theoretical results available for this molecule in more detail than for the other compounds investigated.

Methyl carbamate is a structural isomer of the simplest amino acid, glycine, $\mathrm{H}_{2} \mathrm{NCH}_{2} \mathrm{COOH}$. $\mathrm{MC}$ has a series of biological effects, and there are pharmaceutical applications of these. ${ }^{8}$ Detection of MC in interstellar space appears to be plausible because it might be more abundant than glycine, as its energy is lower, and because its rotational spectrum, investigated in the laboratory, ${ }^{8,9}$ is more intense. In the one conformer of MC found in the laboratory, the methyl and carbonyl groups are in syn conformation (Figure 1). This observation received confirmation by electronic structure computations. ${ }^{9}$ Components of the dipole moment vector of MC were determined experimentally by the Stark effect. ${ }^{8}$ Accurate values of the ${ }^{14} \mathrm{~N}$ quadrupole coupling constants and of the centrifugal distortion constants were determined by Fourier transform microwave (MWFT) and millimeterwave (MMW) spectroscopies, respectively. ${ }^{9}$ An approximate and preliminary value for the barrier to internal rotation of the methyl group in MC has also been determined in ref 9 .

Contrary to glycine, for which accurate estimates of $r_{\mathrm{e}}^{\mathrm{BO}}$ of the two lowest-energy conformers, Gly-Ip and Gly-IIn, ${ }^{10}$ have become available, ${ }^{10-13}$ there is no accurate equilibrium structure available for MC. One of the goals of the present paper is to fill this gap. As part of this work, the spectroscopic constants of $\mathrm{MC}$, including its dipole moment components, quartic centrifugal distortion constants, harmonic and anharmonic vibrational frequencies, and quadrupole coupling constants, are calculated ab initio. An additional aim of this study has been to check the predictive power of lower-level ab initio methods in prevision of spectroscopic studies of larger molecules of biological interest and of structure similar to MC. Finally, the potential curve of and barrier to the methyl internal rotation is calculated as this motion also affects the determination of the equilibrium structure of MC. It is known that sophisticated ab initio methods permit the accurate determination of potential curves and the associated barriers of small molecules, ${ }^{14,15}$ but there is a lack of reliable information for larger molecules.

The paper is organized in the following way. Section 2 describes the computational methods used for the detailed study of the different molecules. Section 3 is dedicated to the equilibrium and effective structures of formamide (3.1), cyanamide (3.2), acetamide (3.3), urea (3.4), carbamic acid (3.5), and methyl carbamate (3.6). For methyl carbamate, the different aspects studied include its ab initio structure (3.6.1), planarity of the CONH linkage (3.6.2), the barrier to internal rotation (3.6.3), the harmonic force field and the subsequent centrifugal distortion constants (3.6.4), and the quadrupole coupling constants (3.6.5). In sections 3.7 and 3.8, $\mathrm{CO}$ and $\mathrm{CN}$ bond lengths are investigated employing a series of molecules structurally similar to MC. Finally, section 4 contains the conclusions of this study.

\section{Methods of Computation}

Most correlated-level ab initio electronic structure computations of this study have been carried out at two levels: secondorder Møller-Plesset perturbation theory (MP2) ${ }^{16}$ and coupled cluster (CC) theory with single and double excitation ${ }^{17}$ augmented by a perturbational estimate of the effects of connected triple excitations $[\mathrm{CCSD}(\mathrm{T})] .{ }^{18}$ The Kohn-Sham density functional theory ${ }^{19}$ using Becke's three-parameter hybrid exchange functional ${ }^{20}$ and the Lee-Yang-Parr correlation functional, ${ }^{21}$ together denoted as B3LYP, was also used extensively in this study. Restricted Hartree-Fock (RHF) calculations, even when not serving as references for the MP2 and $\operatorname{CCSD}(\mathrm{T})$ treatments, have also been performed.

The correlation-consistent polarized $n$-tuple zeta basis sets cc-pVnZ $\mathrm{Z}^{22}$ with $n \in\{\mathrm{D}, \mathrm{T}, \mathrm{Q}, 5\}$ were employed extensively in this study. In this paper, these basis sets are abbreviated as $\mathrm{V} n \mathrm{Z}$. We also used mixed basis sets composed of, for example, V5Z on all non-hydrogen atoms and VQZ on $\mathrm{H}$, denoted as $\mathrm{V}(5, \mathrm{Q}) \mathrm{Z}$. Such basis sets are supposed to lead to little loss in accuracy compared to the use of the full set on all atoms while reducing the computation time significantly. ${ }^{23}$ For several $\operatorname{CCSD}(\mathrm{T})$ calculations, especially geometry optimizations, a mixed basis set denoted as V(T,D)Z was utilized. To account for the electronegative character of the $\mathrm{N}$ and $\mathrm{O}$ atoms, the augmented $\mathrm{V} n \mathrm{Z}$ (aug-cc-pVnZ, $\mathrm{AV} n \mathrm{Z}$ in short) basis sets ${ }^{24}$ were also employed, especially at the MP2 level. The combination of an AVQZ basis on all non-hydrogen atoms and of VQZ on $\mathrm{H}$ is denoted hereafter as $\mathrm{A}^{\prime} \mathrm{VQZ}$. A few calculations were also performed with the split-valence basis sets 3-21G, 6-31G, and $6-311 \mathrm{G}$, as implemented in Gaussian $03,{ }^{25}$ including, in cases, appropriate polarization functions.

In order to estimate the core-core and core-valence correlation effects on the computed properties, especially on 
TABLE 1: Molecular Structure of Formamide, $\mathrm{HCONH}_{2}$, with Distances $(r)$ in $\AA$ and Angles $(\angle)$ in Degrees ${ }^{a}$

\begin{tabular}{|c|c|c|c|c|c|c|c|c|c|c|}
\hline type & & $r(\mathrm{C}-\mathrm{N})$ & $r(\mathrm{C}=\mathrm{O})$ & $r\left(\mathrm{NH}_{\mathrm{s}}\right)$ & $r\left(\mathrm{NH}_{\mathrm{a}}\right)$ & $r(\mathrm{CH})$ & $\angle \mathrm{OCN}$ & $\angle \mathrm{CNH}_{\mathrm{s}}$ & $\angle \mathrm{CNH}_{\mathrm{a}}$ & $\angle \mathrm{HCN}$ \\
\hline$r_{\mathrm{e}}^{\mathrm{BO}}$ & this work & 1.3547 & 1.2097 & 1.0033 & 1.0006 & 1.1001 & 124.63 & 119.18 & 121.09 & 112.53 \\
\hline$r_{\mathrm{e}}$ & ref 3 & 1.354 & 1.212 & 1.003 & 1.000 & 1.097 & 125.0 & 119.3 & 121.1 & 112.0 \\
\hline$r_{\mathrm{s}}^{\mathrm{e}}$ & ref 6 & 1.352 & 1.219 & 1.002 & 1.002 & 1.098 & 124.7 & 118.5 & 119.9 & 112.7 \\
\hline $\mathrm{SRB}^{b}$ & ref 43 & $1.358(3)$ & 1.2139 & $1.0069^{c}$ & $1.0043^{c}$ & $1.106^{c}$ & $124.61(10)$ & $119.4(16)$ & $121.35(58)$ & $d$ \\
\hline$r_{m}^{(2)}$ & this work & $1.361(4)$ & $1.210(4)$ & $1.005(2)$ & $0.984(4)$ & $1.112(3)$ & $124.8(4)$ & $117.8(3)$ & $121.8(5)$ & $112.3(20)$ \\
\hline
\end{tabular}

${ }^{a}$ See Table S1 for more details. $s=$ syn (respectively $a=$ anti) with respect to $\mathrm{C}=\mathrm{O}$ bond. ${ }^{b} \mathrm{SRB}=$ semirigid bender model. ${ }^{c}$ Fixed at the 6-311G(d,p) MP2 value. ${ }^{d}$ Not determined.

equilibrium structures, ${ }^{26}$ the correlation-consistent polarized weighted core-valence $n$-tuple zeta $(\mathrm{cc}-\mathrm{pwCV} n \mathrm{Z})^{27,28}$ and the original cc-pCVnZ basis sets were employed. As for the effect of inclusion of diffuse functions in the basis, it is sufficient to use the MP2 method to estimate this correction. ${ }^{29}$ The frozencore approximation (hereafter denoted as FC), i.e., keeping the 1s orbitals of $\mathrm{C}, \mathrm{N}$, and $\mathrm{O}$ doubly occupied during correlatedlevel calculations, was used extensively. Due partly to technical limitations, geometry optimizations at the CCSD(T) level have also been carried out by correlating all electrons (hereafter denoted as AE).

The $\operatorname{CCSD}(\mathrm{T})$ calculations were performed with the MOLPRO $^{30-32}$ and ACESII ${ }^{33}$ electronic structure program packages, while most other calculations utilized the Gaussian 03 program. ${ }^{25}$

\section{Equilibrium and Effective Structures}

It is well-established that the $\operatorname{CCSD}(\mathrm{T})$ technique usually allows determination of reliable molecular properties. ${ }^{34}$ However, this sophisticated technique of electronic structure theory is rather expensive, as far as computer time and memory is concerned for molecules of the size studied in this paper. The much simpler and consequently much more readily affordable MP2 method can also be remarkably accurate for the determination of equilibrium structures, ${ }^{35}$ provided all atoms belong to the first row and the systematic nature of the computational errors is taken into account. Some error, which is due to the finite size of the basis applied, unless the computed results are extrapolated to the complete basis set (CBS) limit, and to the partial consideration of electron correlation, remains in bond lengths. This error, usually called offset, ${ }^{36}$ is mainly systematic and may be estimated with the help of molecules whose structure is accurately known. The offset values can then be used to improve the accuracy of Born-Oppenheimer equilibrium bond lengths computed by electronic structure techniques of lesser quality. For example, for the $\mathrm{C}-\mathrm{H}$ bond length, the offset is nearly independent of the environment and may thus be easily estimated. ${ }^{37}$ This remains true for the $\mathrm{N}-\mathrm{H}$ bond length of different molecules, with exceptions, such as HNO. ${ }^{38}$ For other bonds, the magnitude of the offset value is somewhat dependent upon environmental perturbations, ${ }^{39}$ and it is essential to determine the offset from structurally similar molecules. To the best of our knowledge, there is no accurate determination of equilibrium values of the $\mathrm{C}-\mathrm{N}$ single bond length and the related offsets. This is one of the reasons why, in this study, we have thoroughly investigated the structures of molecules that have $\mathrm{CN}$ bonds. MP2 may give reliable Born-Oppenheimer equilibrium bond angles, with an accuracy of a few tenths of a degree. ${ }^{40}$ However, for dihedral angles, including that describing the amide linkage, the situation is less favorable, as also seen below.

In order to save space, only the final best representation of the equilibrium structure, $r_{\mathrm{e}}^{\mathrm{BO}}$, is given in the main part of the article. The complete list of ab initio structural results obtained during this study is given in tables of the Supporting Information labeled $\mathrm{S} 1-\mathrm{S} 6$. There a brief discussion is also given how $r_{\mathrm{e}}^{\mathrm{BO}}$ of the different molecules were derived.

The CC $T_{1}$ diagnostic $^{41}$ has been obtained for all molecules. It is comfortably small in all cases studied. Its range at the frozen-core VQZ CCSD(T) level is from 0.0097 for dimethylether to 0.0156 for formamide, indicating that non-dynamical electron correlation is not particularly important and the $\operatorname{CCSD}(\mathrm{T})$ results obtained are reliable.

3.1. Formamide, $\mathbf{H C}(\mathrm{O}) \mathbf{N H}_{2}$. Many studies have been devoted to the structure of formamide (FA). In particular, Fogarasi and Szalay ${ }^{3}$ investigated the question of planarity of FA and computed estimates of its $r_{\mathrm{e}}^{\mathrm{BO}}$ at levels of theory up to all-electron VTZ CCSD(T). They also determined a best theoretical estimate of $r_{\mathrm{e}}^{\mathrm{BO}}$ and compared it to the available vibrationally averaged experimental structures (Table 1). There is an empirical structure of FA determined using the semirigid bender (SRB) model and the experimental ground-state rotational constants of 14 isotopologues. ${ }^{42}$ Later this structure was improved significantly. ${ }^{43}$ An empirical $r_{\mathrm{s}}$ structure of FA is also available. ${ }^{6}$ These studies show beyond a reasonable doubt that FA has a planar equilibrium structure, a very shallow singleminimum inversion potential, and consequently a planar effective ground-state structure, as well.

Besides lower-level estimates, in this study the $\operatorname{CCSD}(\mathrm{T})$ method with the (A) $\mathrm{V} n \mathrm{Z}$ basis sets up to $n=5$ was used for obtaining ab initio estimates of $r_{\mathrm{e}}^{\mathrm{BO}}$ of FA. Both frozen-core and all-electron geometry optimizations have been performed (Table S1). The most important result of the extensive geometry optimizations of this study is the confirmation of the planarity of the equilibrium structure of FA. In particular, all CCSD(T) calculations, including the one with the $\mathrm{V}(\mathrm{T}, \mathrm{D}) \mathrm{Z}$ basis set, result in a planar equilibrium structure.

Formamide is a molecule well suited to check the accuracy of the mass-dependent methods of Watson et al. ${ }^{44}$ resulting in so-called $r_{\mathrm{m}}$ structures, because rotational constants are available for 16 isotopologues. ${ }^{42}$ On the other hand, there is one large amplitude motion in formamide, and furthermore, there are several small coordinates in the principal-axis system $[a(\mathrm{C}) \approx$ $-0.09 \AA, b(\mathrm{O}) \approx-0.21 \AA$, and $b(\mathrm{~N}) \approx-0.16 \AA]$. The result of this analysis is given in Table 1 . With the exception of the $\mathrm{C}-\mathrm{H}$ and $\mathrm{N}-\mathrm{H}$ bond lengths, which cannot be determined accurately by this method (the basic assumption of the $r_{\mathrm{m}}$ methods is that the differences in the mass of the substituted atoms between isotopologues is small, which does not hold for the substitution of hydrogen atoms), the two-parameter $r_{\mathrm{m}}^{(2)}$ structure of this study is in considerably better agreement with $r_{\mathrm{e}}^{\mathrm{BO}}$ than the $r_{\mathrm{s}}$ structure. This is an indication that the $r_{\mathrm{m}}^{(2)}$ method might also be used in the presence of a large-amplitude motion. This confirms the results recently found by Kisiel ${ }^{45}$ on the structure of weakly bound clusters.

It was also attempted to determine a semi-experimental equilibrium structure of formamide as follows. A complete cubic force field has been determined at the all-electron VTZ MP2 
TABLE 2: Structure of Cyanamide, $\mathrm{H}_{2} \mathrm{NCN}$, with Distances $(r)$ in $\AA$ and Angles $(\angle)$ in Degrees ${ }^{a}$

\begin{tabular}{llllllll}
\hline type & & $r(\mathrm{C} \equiv \mathrm{N})$ & $r(\mathrm{~N}-\mathrm{C})$ & $r(\mathrm{~N}-\mathrm{H})$ & $\angle \mathrm{HNC}$ & $\tau$ & $\angle \mathrm{NCN}$ \\
\hline$r_{\mathrm{e}}^{\mathrm{BO}}$ & this & 1.1587 & 1.3482 & 1.0072 & 113.39 & 115.39 & 177.06 \\
& work & & & & & & \\
$\mathrm{SRB}$ & ref 49 & 1.1645 & $1.3301(5)$ & 0.9994 & $b$ & $b$ & 174.8 \\
$r_{\mathrm{s}}$ & ref 50 & $1.160(5)$ & $1.346(5)$ & $1.001(15)$ & 115.6 & 112.0 & $180^{b}$
\end{tabular}

${ }^{a}$ See Table $\mathrm{S} 2$ for more details. SRB $=$ semirigid bender. $\tau=$ dihedral angle $(\mathrm{NCN}, \mathrm{CNH})$. For a planar molecule $2 \angle \mathrm{HNC}+\angle \mathrm{HNH}$ should be $360^{\circ}$, but in the present case, it is only $338.8^{\circ}$ for $r_{\mathrm{e}}^{\mathrm{BO}} \cdot{ }^{b}$ Not given or fixed in the original work.

level using built-in features ${ }^{46}$ of the ACESII code. ${ }^{33}$ The calculation was performed at the corresponding optimized reference geometry to avoid problems associated with nonzero forces. ${ }^{47}$ This force field has been used to determine the vibration-rotation interaction constants $\alpha_{i}^{\xi}$, where $\xi=A, B, C$ and $i=1, \ldots, 12$, counting the vibrational modes, for 16 isotopologues of formamide, all for which ground-state rotational constants are available. The (lowest-order) $\alpha_{i}^{\xi}$ constants have been used, through standard formulas, ${ }^{48}$ to deduce equilibrium rotational constants. However, although the $v_{12}=1$ mode (the large-amplitude $\mathrm{NH}_{2}$ inversion motion at $288.7 \mathrm{~cm}^{-1}$ ) is well isolated, the calculated $\alpha_{12}^{\mathrm{A}}=2039 \mathrm{MHz}$ and $\alpha_{12}^{\mathrm{C}}=28.9 \mathrm{MHz}$ are in poor agreement with the corresponding experimental values, 978 and $-0.0099 \mathrm{MHz}$, respectively. ${ }^{43}$ This problem is reflected in the value of the equilibrium inertial defect which should be 2 orders of magnitude smaller than the ground-state inertial defect but in fact it is larger: $\Delta_{\mathrm{e}}=0.086 \mathrm{u}^{2}$ to be compared with $\Delta_{0}=0.007 \mathrm{u} \AA{ }^{2}$ Whereas the $r(\mathrm{C}-\mathrm{N})$, $r(\mathrm{C}=\mathrm{O})$, and $r(\mathrm{C}-\mathrm{H})$ bond lengths are rather well reproduced, the semi-experimental $r(\mathrm{~N}-\mathrm{H})$ bond lengths are much too long (best computational estimate for $r_{\mathrm{e}}^{\mathrm{BO}}$ in parentheses): $r\left(\mathrm{~N}-\mathrm{H}_{\mathrm{s}}\right)$ $=1.007(1.003) \AA$ and $r\left(\mathrm{~N}-\mathrm{H}_{\mathrm{a}}\right)=1.013$ (1.001) $\AA$. This poor agreement is not surprising since the force field is calculated assuming that the amplitude of the vibrations is small, whereas the inversion is a large amplitude vibration. In conclusion, the semi-experimental method as given above has to be used with caution for decidedly non-rigid molecules.

3.2. Cyanamide, $\mathbf{H}_{2} \mathbf{N C N}$. Several investigations attempted to determine $r_{\mathrm{e}}^{\mathrm{BO}}$ of cyanamide. Unlike planar formamide, cyanamide has an equilibrium configuration pyramidal about N. An empirical structure was determined using the SRB model and the ground-state rotational constants of seven isotopologues. ${ }^{49}$ An empirical $r_{\mathrm{s}}$ structure of cyanamide has been determined by Tyler et al. ${ }^{50}$ Kapellos and Mavridis ${ }^{51}$ have calculated an ab initio $r_{\mathrm{e}}$ structure using the singles and doubles configuration interaction (CISD) technique. In this study, the $r_{\mathrm{e}}^{\mathrm{BO}}$ structure of cyanamide was determined following geometry optimizations at several levels of electronic structure theory (Tables 2 and S2).

The range of variation of $r_{\mathrm{e}}(\mathrm{C} \equiv \mathrm{N})$ is known to be quite small, see for instance Table 6 of ref 52. The $r_{\mathrm{e}}^{\mathrm{BO}}$ value found for cyanamide in this study, $1.159 \AA$, lies in the predicted range but is significantly smaller than the value of $1.1645 \AA$ assumed by Brown et al. ${ }^{49}$ in their SRB analysis. This is probably the reason why the true $\mathrm{C}-\mathrm{N}$ bond at $r_{\mathrm{e}}^{\mathrm{BO}}=1.348 \AA$ is considerably longer than the value of 1.3301(5) $\AA$ derived in ref 49 . The accuracy of the $r_{\mathrm{e}}^{\mathrm{BO}}$ bond angles of cyanamide is thought to be as good as $0.2^{\circ}$, whereas that of the dihedral angle may be as low as $1^{\circ}$.

3.3. Acetamide, $\mathrm{CH}_{3} \mathrm{CONH}_{2}$. Acetamide, the methyl derivative of formamide, is of special interest because of its very low barrier to internal rotation $\left(V_{3}=25 \mathrm{~cm}^{-1}\right)^{53}$ that has a huge effect on the rotational spectrum. For this reason, the MW spectrum of acetamide was investigated several times. See, for instance, two recent papers 53,54 which review earlier work. In all of the MW works, it was assumed that the frame of the molecule has $C_{s}$ symmetry; that is, all of the atoms lie in the same plane except two of the methyl H's. ${ }^{55}$ This assumption was verified by a careful analysis of the MW spectrum that clearly indicates that the huge internal rotation splittings are perfectly accounted for assuming a $C_{s}$ symmetry for the frame of the molecule, ${ }^{53}$ with the MW data fitted with a standard deviation of $26 \mathrm{kHz}$ for 1706 lines in the $v_{\mathrm{t}}=0,1$, and 2 torsional states, a result which is clearly within the experimental accuracy. Absence of an out-of-plane component of the dipole moment from Stark measurements and absence of $c$-type transitions also strengthen a planar ground state structure for the frame.

This assumed planarity of the frame seems to have been first based on an early gas electron diffraction (GED) analysis ${ }^{56}$ where, actually, it was already assumed that the amide group is planar. This assumption was later strengthened by two farinfrared (FIR) vapor-phase spectral studies. ${ }^{57,58}$ As to the equilibrium structure, a recent ab initio work ${ }^{59}$ concluded that the amino group might be slightly pyramidal. Moreover, in the same ab initio study, it was also shown that a $\mathrm{C}-\mathrm{H}$ bond of the methyl top is almost perpendicular to the plane of nonhydrogen atoms, hereafter called a perpendicular conformation, which seems to be also the most stable form in the solid state. Samdal ${ }^{60}$ computed several ab initio force fields and found that the best agreement between the calculations and the experimental gas-phase vibrational frequencies is obtained with the perpendicular conformation and a planar $\mathrm{NH}_{2}$ group.

MW studies of the parent isotopologue cannot tell which conformation, one $\mathrm{C}-\mathrm{H}$ being syn (eclipsed with the oxygen), anti, or perpendicular to the plane of non-hydrogen atoms, is the most stable in the gas phase because MW studies correspond to an average of the structures while the $\mathrm{CH}_{3}$ group is internally rotating. For example, the out-of-plane dipole moment component, $\mu_{\mathrm{c}}$, is zero in the syn and anti conformations and also averages to zero for all torsional angles in the case of the perpendicular conformation. The only information MW studies yield is that the assumption of a planar heavy-atom skeleton agrees, within experimental accuracy, with results of a fitting of the data to an "in-plane" Hamiltonian. Likewise, if the $\mathrm{NH}_{2}$ group is slightly out of the plane, it is likely that the higherorder rotation-torsion terms used in the Hamiltonian are going to "absorb" this small effect.

The structure of acetamide was optimized in this study at several advanced levels of electronic structure theory (Tables 3 and S3). Our calculations on formamide (section 3.1 and Tables 1 and S1) and urea (section 3.4 and Tables 4 and S4), as well as on carbamic acid (section 3.5 and Tables 5 and S5), indicate that the all-electron V(T,D)Z CCSD(T) level is accurate enough to predict the structure of the heavy atom skeleton. The ab initio calculations of this study confirm beyond reasonable doubt that the perpendicular conformation is the preferred equilibrium structure of acetamide. The calculated value of the angle $\angle(i$, $c$ ) between the internal rotation axis $i$ and the principal axis $c$ is $89.78^{\circ}$. To analyze the internal rotation splittings, a value of $90^{\circ}$ was assumed for this angle and as mentioned above, this assumption leads to an excellent standard deviation in a global fit. The two structures, the one deduced ab initio and the one from experimental MW and FIR data can be understood if one takes into account the qualitative difference between an equilibrium structure, which corresponds to the minimum of the 
TABLE 3: Structure of Acetamide, $\mathrm{CH}_{3} \mathrm{C}(\mathrm{O}) \mathrm{NH}_{2}$, with Distances $(r)$ in $\AA$ and Angles $(\angle$ and $\tau)$ in Degrees ${ }^{a}$

\begin{tabular}{|c|c|c|}
\hline parameter & $r_{\mathrm{e}}^{\mathrm{BO}}$ & $r_{\mathrm{g}}^{56}$ \\
\hline$r\left(\mathrm{NH}_{\mathrm{s}}\right)$ & 1.003 & \\
\hline$r\left(\mathrm{NH}_{\mathrm{t}}\right)$ & 1.000 & \\
\hline$r(\mathrm{CN})$ & 1.362 & $1.380(4)$ \\
\hline$r(\mathrm{C}=\mathrm{O})$ & 1.216 & $1.220(3)$ \\
\hline$r(\mathrm{CC})$ & 1.509 & $1.519(6)$ \\
\hline$r\left(\mathrm{CH}_{1}\right)$ & 1.082 & \\
\hline$r\left(\mathrm{CH}_{2}\right)$ & 1.086 & \\
\hline$r\left(\mathrm{CH}_{3}\right)$ & 1.085 & \\
\hline$\angle(\mathrm{HNH})$ & 119.28 & \\
\hline$\angle\left(\mathrm{CNH}_{\mathrm{s}}\right)$ & 118.05 & \\
\hline$\angle\left(\mathrm{CNH}_{\mathrm{t}}\right)$ & 121.84 & \\
\hline$\angle(\mathrm{NCO})$ & 122.20 & $122.0(6)$ \\
\hline$\angle(\mathrm{NCC})$ & 115.11 & 115.1(16) \\
\hline$\angle(\mathrm{OCC})$ & 122.69 & 123.0 \\
\hline$\angle\left(\mathrm{CCH}_{1}\right)$ & 108.68 & \\
\hline$\angle\left(\mathrm{CCH}_{2}\right)$ & 108.63 & \\
\hline$\angle\left(\mathrm{CCH}_{3}\right)$ & 112.73 & \\
\hline$\angle\left(\mathrm{H}_{1} \mathrm{CH}_{2}\right)$ & 108.19 & \\
\hline$\angle\left(\mathrm{H}_{1} \mathrm{CH}_{3}\right)$ & 109.86 & \\
\hline$\angle\left(\mathrm{H}_{2} \mathrm{CH}_{3}\right)$ & 108.65 & \\
\hline$\tau\left(\mathrm{OCNH}_{\mathrm{s}}\right)$ & -5.39 & \\
\hline$\tau\left(\mathrm{CCNH}_{\mathrm{s}}\right)$ & 173.92 & \\
\hline$\tau\left(\mathrm{OCNH}_{\mathrm{t}}\right)$ & -174.88 & \\
\hline$\tau\left(\mathrm{CCNH}_{\mathrm{t}}\right)$ & 4.44 & \\
\hline$\tau\left(\mathrm{NCCH}_{1}\right)$ & 147.98 & \\
\hline$\tau\left(\mathrm{NCCH}_{2}\right)$ & -94.52 & \\
\hline$\tau\left(\mathrm{NCCH}_{3}\right)$ & 25.94 & \\
\hline$\tau\left(\mathrm{OCCH}_{1}\right)$ & -32.71 & \\
\hline$\tau\left(\mathrm{OCCH}_{2}\right)$ & 84.79 & \\
\hline$\tau\left(\mathrm{OCCH}_{3}\right)$ & -154.75 & \\
\hline
\end{tabular}

${ }^{a}$ See Table $\mathrm{S} 3$ for more details. The hydrogen $\mathrm{H}_{2}$ is approximately perpendicular to the heavy-atom plane. $s=\operatorname{syn}($ respectively $a=$ anti) with respect to the $\mathrm{C}=\mathrm{O}$ bond. For a planar molecule, $2 \angle \mathrm{HNC}+$ $\angle \mathrm{HNH}$ should be $360^{\circ}$, but in the present case, it is $359.2^{\circ}$ for $r_{\mathrm{e}}^{\mathrm{BO}}$.

TABLE 4: Structure of Urea, $\mathrm{OC}\left(\mathrm{NH}_{2}\right)_{2}$, with Distances $(r)$ in $\AA$ and Angles $(\angle$ and $\tau)$ in Degrees ${ }^{a}$

\begin{tabular}{lcc}
\hline parameter & $r_{\mathrm{s}}^{61}$ & $r_{\mathrm{e}}^{\mathrm{BO}}$ \\
\hline$r(\mathrm{C}=\mathrm{O})$ & 1.2211 & 1.2116 \\
$r(\mathrm{C}-\mathrm{N})$ & 1.3779 & 1.3817 \\
$r\left(\mathrm{NH}_{\mathrm{s}}\right)$ & 0.9978 & 1.0047 \\
$r\left(\mathrm{NH}_{\mathrm{a}}\right)$ & 1.0212 & 1.0047 \\
$\angle(\mathrm{OCN})$ & 122.64 & 123.17 \\
$\angle\left(\mathrm{CNH}_{\mathrm{s}}\right)$ & 119.21 & 116.73 \\
$\angle\left(\mathrm{CNH}_{\mathrm{a}}\right)$ & 112.78 & 112.63 \\
$\tau\left(\mathrm{NCNH}_{\mathrm{s}}\right)$ & 23.2 & 30.62 \\
$\tau\left(\mathrm{NCNH}_{\mathrm{a}}\right)$ & 169.2 & 165.79
\end{tabular}

${ }^{a}$ See Table S4 for more details. For a planar molecule, $2 \angle \mathrm{HNC}+$ $\angle \mathrm{HNH}$ should be $360^{\circ}$, but in the present case, it is only $343.7^{\circ}$ for $r_{\mathrm{e}}^{\mathrm{BO}}$.

potential, given ab initio, and a ground-state structure, which corresponds here to a vibrational-torsional average given by experiments. This idea is supported by the fact that the groundstate inertial defect is $\Delta_{0}=3.10 \mathrm{u}^{2}, 53$ whereas the equilibrium value is $\Delta_{\mathrm{e}}=3.19 \mathrm{u} \AA^{2}$, giving a vibrational contribution $\Delta_{\mathrm{v}}=$ $0.09 \mathrm{u}^{2}$. Assuming that the vibrational contribution can be calculated from the harmonic force field and using the scaled ab initio force field of Samdal, ${ }^{60}$ we get $\Delta_{\mathrm{v}}=0.09 \mathrm{u} \AA^{2}$, in perfect agreement with the experimental value. This shows that the small positive vibrational contribution to the inertial defect is compatible with a nonplanar equilibrium structure.

3.4. Urea, $\mathrm{H}_{2} \mathrm{NCONH}_{2}$. Similarly to formamide, planarity of urea has been the subject of much debate. The early studies are reviewed nicely by Godfrey et al. ${ }^{61}$ These authors also analyzed the MW spectra of several isotopologues of urea which allowed them to obtain an $r_{\mathrm{s}}$ structure (Table 4). They found
TABLE 5: Structure of Carbamic Acid, $\mathrm{H}_{2} \mathrm{NCOOH}$, with Distances $(r)$ in $\AA$ and Angles $(\angle$ and $\tau)$ in Degrees ${ }^{a}$

\begin{tabular}{lclc}
\hline \multicolumn{1}{c}{ parameter } & $r_{\mathrm{e}}^{\mathrm{BO}}$ & \multicolumn{1}{c}{ parameter } & $r_{\mathrm{e}}^{\mathrm{BO}}$ \\
\hline$r(\mathrm{C}-\mathrm{N})$ & 1.3569 & $r(\mathrm{C}=\mathrm{O})$ & 1.2083 \\
$r\left(\mathrm{~N}-\mathrm{H}_{\text {cis }}=\mathrm{O}\right)$ & 1.0025 & $r(\mathrm{C}-\mathrm{O})$ & 1.3622 \\
$r\left(\mathrm{~N}-\mathrm{H}_{\text {trans }}\right)$ & 1.0031 & $r(\mathrm{O}-\mathrm{H})$ & 0.9654 \\
$\angle \mathrm{CNH}_{\text {cis }}$ & 117.58 & $\angle \mathrm{C}-\mathrm{O}-\mathrm{H}$ & 105.77 \\
$\angle \mathrm{CNH} H_{\text {trans }}$ & 120.40 & $\angle \mathrm{O}-\mathrm{C}-\mathrm{N}-\mathrm{H}_{\text {cis }}$ & 9.10 \\
$\angle \mathrm{HNH}$ & 119.48 & $\angle \mathrm{O}=\mathrm{C}-\mathrm{N}-\mathrm{H}_{\text {cis }}$ & -171.90 \\
$\angle \mathrm{N}-\mathrm{C}=\mathrm{O}$ & 125.88 & $\angle \mathrm{O}-\mathrm{C}-\mathrm{N}-\mathrm{H}_{\text {trans }}$ & 170.93 \\
$\angle \mathrm{N}-\mathrm{C}-\mathrm{O}$ & 110.62 & $\angle \mathrm{O}=\mathrm{C}-\mathrm{N}-\mathrm{H}_{\text {trans }}$ & -10.07 \\
$\angle \mathrm{O}=\mathrm{C}-\mathrm{O}$ & 123.49 & & \\
$\tau(\mathrm{NCOH})$ & -178.75 & $\tau(\mathrm{OCOH})$ & 0.28
\end{tabular}

${ }^{a}$ See Table S5 for more details. For a planar molecule, $2 \angle \mathrm{HNC}+$ $\angle \mathrm{HNH}$ should be $360^{\circ}$, but in the present case, it is only $357.5^{\circ}$ for $r_{\mathrm{e}}^{\mathrm{BO}}$.

that the conformer of lowest energy has $C_{2}$ symmetry and that a structure of $C_{s}$ symmetry has a slightly higher energy.

The new high-level calculations of this study (Tables 4 and $\mathrm{S} 4$ ) confirm that the equilibrium structure of urea belongs to $C_{2}$ point-group symmetry. It may be noted that several parameters of the equilibrium structure are rather far from the $r_{\mathrm{s}}$ structure parameters derived in ref 61 . This is not surprising because it is well-established that $r_{\mathrm{s}}(\mathrm{XH})$ distances are not reliable. Furthermore, the rotational constants of the ${ }^{13} \mathrm{C}$ isotopologue were not determined, which explains the inaccuracy of the $r_{\mathrm{s}}(\mathrm{C}=\mathrm{O})$ bond length.

3.5. Carbamic Acid, $\mathrm{H}_{2} \mathbf{N C O O H}$. Methyl carbamate is an ester of carbamic acid (CA). Before investigating the structure of $\mathrm{MC}$, it is important to check whether CA has a planar or nonplanar equilibrium heavy-atom framework, because the nonplanarity of some peptide linkages has been attributed to the low potential barrier of a methyl substituent. ${ }^{7}$

$\mathrm{CA}$ has not yet been characterized in the gas phase by any experimental technique, although its zwitterion, $\mathrm{H}_{3}{ }^{+} \mathrm{NCOO}^{-}$, has been identified by infrared spectroscopy in the solid phase. ${ }^{62}$ The structure of carbamic acid has been determined at the HF level using the $4-21 G^{63}$ and $6-31 G^{* 64}$ basis sets. In both cases, the planar trans form, with the hydroxyl hydrogen trans to $\mathrm{N}$, was found to be the most stable one.

The structure of CA was optimized in this study (Tables 5 and S5). Although the $\angle(\mathrm{OCNH})$ dihedral angles show considerable variation with the level of theory, imposing the constraint of planarity during optimization always resulted in one imaginary vibrational frequency. Therefore, we can conclude that the $r_{\mathrm{e}}^{\mathrm{BO}}$ structure of carbamic acid is not planar. It has to be noted, at the same time, that the energy difference between the planar and nonplanar forms is rather small, only $20-30 \mathrm{~cm}^{-1}$ at the all-electron CCSD(T) level with basis sets V(T,D)Z, VTZ, and AVTZ.

3.6. Methyl Carbamate. This section involves the most detailed discussion among the molecules considered, and thus, it is divided into subsections. The results relevant for MC are presented in Tables 6-11 and in Table 13, as well as in Table S6.

3.6.1. Equilibrium Structures. An estimate of $r_{\mathrm{e}}^{\mathrm{BO}}$ of MC is given in Table 6 (see Table S6 for more detailed computed results). All geometry optimizations indicate that in MC the amide group is slightly nonplanar at equilibrium. This is in apparent contrast to results of MW investigations, ${ }^{8,9}$ measurement of the vibrationally averaged dipole moment of MC clearly shows that the molecule has a plane of symmetry, as $\mu_{\mathrm{c}}$ is zero. Fogarasi and Szalay ${ }^{3}$ have demonstrated that MP2 optimizations wrongly predict a nonplanar structure for formamide, but in their 
TABLE 6: Estimate of Born-Oppenheimer Equilibrium Structure of Methyl Carbamate with Distances in $\AA$ and Angles in Degrees ${ }^{a}$

\begin{tabular}{lllr}
\hline parameter & $r_{\mathrm{e}}^{\mathrm{BO}}$ & parameter & \multicolumn{1}{c}{$r_{\mathrm{e}}^{\mathrm{BO}}$} \\
\hline $\mathrm{N}_{1}-\mathrm{C}_{2}$ & 1.362 & $\mathrm{O}_{4} \mathrm{C}_{5} \mathrm{H}_{6}$ & 110.57 \\
$\mathrm{~N}_{1}-\mathrm{H}_{9}$ & 1.002 & $\mathrm{O}_{4} \mathrm{C}_{5} \mathrm{H}_{7}$ & 110.50 \\
$\mathrm{~N}_{1}-\mathrm{H}_{10}$ & 1.002 & $\mathrm{O}_{4} \mathrm{C}_{5} \mathrm{H}_{8}$ & 105.44 \\
$\mathrm{C}_{2}=\mathrm{O}_{3}$ & 1.207 & $\mathrm{H}_{6} \mathrm{C}_{5} \mathrm{H}_{7}$ & 109.11 \\
$\mathrm{C}_{2}-\mathrm{O}_{4}$ & 1.351 & $\mathrm{H}_{6} \mathrm{C}_{5} \mathrm{H}_{8}$ & 110.61 \\
$\mathrm{O}_{4}-\mathrm{C}_{5}$ & 1.429 & $\mathrm{H}_{7} \mathrm{C}_{5} \mathrm{H}_{8}$ & 110.58 \\
$\mathrm{C}_{5}-\mathrm{H}_{6}$ & 1.087 & $\mathrm{H}_{9} \mathrm{~N}_{1} \mathrm{C}_{2} \mathrm{O}_{3}$ & 15.88 \\
$\mathrm{C}_{5}-\mathrm{H}_{7}$ & 1.087 & $\mathrm{H}_{9} \mathrm{~N}_{1} \mathrm{C}_{2} \mathrm{O}_{4}$ & -165.90 \\
$\mathrm{C}_{5}-\mathrm{H}_{8}$ & 1.084 & $\mathrm{H}_{10} \mathrm{~N}_{1} \mathrm{C}_{2} \mathrm{O}_{3}$ & 164.91 \\
$\mathrm{C}_{2} \mathrm{~N}_{1} \mathrm{H}_{9}$ & 115.88 & $\mathrm{H}_{10} \mathrm{~N}_{1} \mathrm{C}_{2} \mathrm{O}_{4}$ & -16.86 \\
$\mathrm{C}_{2} \mathrm{~N}_{1} \mathrm{H}_{10}$ & 118.23 & $\mathrm{~N}_{1} \mathrm{C}_{2} \mathrm{O}_{4} \mathrm{C}_{5}$ & -177.46 \\
$\mathrm{H}_{9} \mathrm{~N}_{1} \mathrm{H}_{10}$ & 118.25 & $\mathrm{O}_{3} \mathrm{C}_{2} \mathrm{O}_{4} \mathrm{C}_{5}$ & 0.79 \\
$\mathrm{~N}_{1} \mathrm{C}_{2} \mathrm{O}_{3}$ & 125.51 & $\mathrm{C}_{2} \mathrm{O}_{4} \mathrm{C}_{5} \mathrm{H}_{6}$ & -60.24 \\
$\mathrm{~N}_{1} \mathrm{C}_{2} \mathrm{O}_{4}$ & 109.92 & $\mathrm{C}_{2} \mathrm{O}_{4} \mathrm{C}_{5} \mathrm{H}_{7}$ & 60.66 \\
$\mathrm{O}_{3} \mathrm{C}_{2} \mathrm{O}_{4}$ & 124.54 & $\mathrm{C}_{2} \mathrm{O}_{4} \mathrm{C}_{5} \mathrm{H}_{5}$ & -179.82 \\
$\mathrm{C}_{2} \mathrm{O}_{4} \mathrm{C}_{5}$ & 113.49 & &
\end{tabular}

${ }^{a}$ See Table S6 for more details. For a planar molecule, $2 \angle \mathrm{HNC}+$ $\angle \mathrm{HNH}$ should be $360^{\circ}$, but in the present case, it is only $352.4^{\circ}$ for $r_{\mathrm{e}}^{\mathrm{BO}}$.

work, the Hartree-Fock (HF) calculations predicted a planar structure. For MC, even the HF calculations predict a nonplanar equilibrium structure (results not presented in Table 6). Furthermore, Kwiatkowski and Leszczynski ${ }^{65}$ have shown that the 6-311G(3df,2p) MP2 level of theory predicts an almost planar structure for formamide. For MC, the same level predicts a nonplanar equilibrium structure. Likewise, Marstokk et al. ${ }^{66}$ have found that the $6-31+G^{*}$ and $6-311++G^{* *}$ MP2 methods do not give a planar structure for acrylamide, whereas both $\mathrm{HF}$ and B3LYP geometry optimizations predict a planar structure. The difference between the energies of the optimized planar and the nonplanar structures of MC is small for all methods considered, the difference is only $53 \mathrm{~cm}^{-1}$ at the all-electron V(T,D)Z CCSD(T) level.

Based on evidence presented for the other $\mathrm{XC}(=\mathrm{O}) \mathrm{NHY}$ molecules investigated, there is no doubt that the nonplanarity predicted at the highest level, all-electron V(T,D)Z CCSD(T), for $r_{\mathrm{e}}^{\mathrm{BO}}$ of $\mathrm{MC}$ is real. The equilibrium inversion (pyramidalization) barrier about $\mathrm{N}$ is small, only about $50 \mathrm{~cm}^{-1}$ at the VTZ CCSD(T) level.

3.6.2. Planarity of the Amide Linkage. Different possible planarity criteria are discussed in this section, like the values of the inertial defect and the quadrupole coupling constants, summarized in Table 7, one of the most important tables of this study, and the electric dipole moments, shown in Table 9. All of this is related to the question of the difference between a nonplanar equilibrium and a seemingly planar effective structure of MC.

Ground-state inertial defects are commonly used as a measure of planarity. If a molecule has a plane of symmetry with only the two methyl hydrogen out of the plane, the ground-state inertial defect may be written as

$$
I_{a}^{0}+I_{b}^{0}-I_{c}^{0}=m_{\mathrm{H}} d_{\mathrm{HH}}^{2}-\Delta_{\mathrm{v}}^{0}
$$

where $d_{\mathrm{HH}}$ is the equilibrium distance between the two out-ofplane hydrogens and $\Delta_{\mathrm{v}}^{0}$ is the vibrational contribution to the ground-state inertial defect. Ab initio calculations are generally reliable in predicting the structure and the distortions occurring within a methyl group in asymmetric environments. ${ }^{15,67}$ For MC, a reasonable value for $d_{\mathrm{HH}}$ is $1.7737 \AA$ (as deduced from Table 6), resulting in an equilibrium inertial defect of $3.1706 \mathrm{u}^{2}$ (see also the last two lines of Table S8 of the Supporting Information which give the inertial defect for the planar form). Using the experimental value of the inertial defect, $3.247 \mathrm{u}^{2}$ (see first line of Table 8) results in $\Delta_{\mathrm{v}}^{0}=+0.076 \mathrm{u}^{2}$. Such a small positive contribution seems at first compatible with a planar equilibrium structure, at least for most molecules. ${ }^{68}$ Nevertheless, for the molecules containing an $\mathrm{NH}$ group studied in the present work we can draw no firm conclusion, as can be seen from the results collected in Table 7.

The vibrational contribution is known to increase with the mass of the molecule. Therefore, the value found for MC is perhaps slightly too small. Furthermore, the values of the calculated inertial defects for the planar and nonplanar forms of $\mathrm{MC}$ are rather close, as can be seen by comparing the last four lines of Table S8 of the Supporting Information. Therefore, it seems difficult to draw any firm conclusion from the inertial defects.

However, there is another way to estimate the equilibrium inertial defect, using experimental ground-state rotational constants and ab initio rovibrational corrections, calculated in this case at the all-electron 6-31G* MP2 level. The corrections are as follows (in MHz): $A_{\mathrm{e}}-A_{0}=82.1, B_{\mathrm{e}}-B_{0}=39.6$, and $C_{\mathrm{e}}$ $-C_{0}=30.8$ (Table 8). This gives $\Delta_{\mathrm{e}}=3.390 \mathrm{u}^{2}$. This value, almost identical to the value obtained from the $r_{\mathrm{e}}^{\mathrm{BO}}$ structure of Table $6,3.38 \mathrm{u}^{2}$, is definitely too large for only two out-ofplane hydrogens, and it is an indication that the molecule is nonplanar at equilibrium. It is possible to go a little bit farther using the mixed regression method, ${ }^{69}$ which is a weighted leastsquares technique, where the ab initio equilibrium structure of Table 6 and the semi-experimental equilibrium constants, i.e., the experimental ground-state rotational constants corrected with the ab initio rovibrational contributions ( $\alpha$ 's), are used as input values (with appropriate weights). The fitted parameters are nearly identical to the original equilibrium structure, the maximum deviations are $0.0010 \AA$ for $r\left(\mathrm{C}_{2}=\mathrm{O}_{3}\right)$ and $-0.13^{\circ}$ for $\angle\left(\mathrm{N}_{1} \mathrm{C}_{2} \mathrm{O}_{4}\right)$, with the exception of the two dihedral angles $\angle\left(\mathrm{H}_{10} \mathrm{~N}_{1} \mathrm{C}_{2} \mathrm{O}_{3}\right)$ and $\angle\left(\mathrm{H}_{9} \mathrm{~N}_{1} \mathrm{C}_{2} \mathrm{O}_{3}\right)$, whose fitted values (with input values in parentheses) are $12.17^{\circ}\left(15.88^{\circ}\right)$ and $159.47^{\circ}$ $\left(164.91^{\circ}\right)$, respectively. These calculations provide further clear evidence that MC has a nonplanar equilibrium structure. However, it has to be mentioned that the planar effective rotational constants are corrected with $\alpha$ 's computed at a nonplanar equilibrium structure. As the rotational constants of the planar and nonplanar forms agree within $10 \mathrm{MHz}$, it is reasonable to assume that the corrections have similar errors. These should have no significant consequence on the structure. The main reason why this assumption is working well is that the $\alpha$ 's that have different values in planar and nonplanar forms are those related to the large amplitude motions, and they are negligible compared to the others.

Next, the quadrupole coupling constants are used to check the planarity of MC. ${ }^{4}$ The $\chi_{c c}$ constant of MC, where $c$ is the principal axis perpendicular to the assumed symmetry plane, should have a value close to those found for similar molecules. From inspection of data in Table 7, it might be concluded that MC has a nonplanar equilibrium structure since nonplanar species have a larger absolute value. However, as shown by the variation of $\chi_{c c}$ for species having a planar ground-state structure, planarity is only one of the factors that affect $\chi_{c c}$. Therefore, it appears somewhat dangerous to draw any conclusion about the planarity of the heavy-atom skeleton of the effective structure based on the value of $\chi_{c c}$.

The dipole moment vector of MC provides possibly the best indicator about the ground-state planarity of the amide linkage. If the heavy-atom skeleton of the molecule in its ground state 
TABLE 7: Quadrupole Coupling Constants, $\chi_{c c}\left({ }^{14} \mathbf{N}\right) / \mathbf{M H z}$, and Vibrational Contributions to the Inertial Defect, $\Delta_{v} / \mathrm{u}^{2}$, of Some NH Derivatives

\begin{tabular}{|c|c|c|c|}
\hline molecule & $\chi_{c c}\left({ }^{14} \mathrm{~N}\right)$ & $\Delta_{\mathrm{v}}{ }^{a}$ & $\begin{array}{l}\text { ground-state } \\
\text { planarity }^{b}\end{array}$ \\
\hline $\begin{array}{l}\mathrm{BH}_{2} \mathrm{NH}_{2} \text { (aminoborane) } \\
\mathrm{BF}_{2} \mathrm{NH}_{2} \text { (aminodifluoroborane) } \\
\mathrm{CH}_{3} \mathrm{NHC}(\mathrm{O}) \mathrm{H} \text { ( } N \text {-methylformamide) } \\
\mathrm{C}_{6} \mathrm{H}_{5} \mathrm{NHCHO} \text { (trans-formanilide) } \\
\mathrm{FCH}_{2} \mathrm{C}(\mathrm{O}) \mathrm{NH}_{2} \text { (2-fluoroacetamide) } \\
\mathrm{HCCC} \mathrm{O}) \mathrm{NH}_{2} \text { (2-propynamide) } \\
\mathrm{CH}_{3} \mathrm{C}(\mathrm{O}) \mathrm{NHCH}_{3} \text { (N-methylacetamide) } \\
\mathrm{NH}_{2} \mathrm{CHO} \text { (formamide) }\end{array}$ & $\begin{array}{l}\text { Planar Equilibrium Structure } \\
\quad-2.186(8)^{c} \\
-3.193(8)^{d} \\
-3.59(30)^{e} \\
-3.671^{f} \\
-3.7008(27)^{h} \\
-3.82(8)^{j} \\
-3.823(3)^{k} \\
-3.848(4)^{m}\end{array}$ & $\begin{array}{c}0.048 \\
0.152 \\
0.15 \\
-0.601^{g} \\
0.102^{i} \\
0.182 \\
0.602^{l} \\
0.007\end{array}$ & $\begin{array}{l}\text { planar } \\
\text { planar } \\
\text { planar } \\
\text { planar } \\
\text { planar } \\
\text { planar } \\
\text { planar } \\
\text { planar }\end{array}$ \\
\hline $\begin{array}{l}\mathrm{CH}_{3} \mathrm{C}(\mathrm{O}) \mathrm{NH}_{2} \text { (acetamide) } \\
\mathrm{OC}\left(\mathrm{NH}_{2}\right)_{2} \text { (urea) } \\
\mathrm{H}_{2} \mathrm{C}=\mathrm{CHNH}_{2} \text { (vinylamine) } \\
\mathrm{C}_{6} \mathrm{H}_{5} \mathrm{NH}_{2} \text { (aniline) } \\
\mathrm{NH}_{2} \mathrm{C}(\mathrm{O}) \mathrm{OCH}_{3} \text { (methyl carbamate) } \\
\mathrm{CH}_{3} \mathrm{NH}_{2} \text { (methylamine) } \\
\mathrm{H}_{2} \mathrm{C}=\mathrm{CHC}(\mathrm{O}) \mathrm{NH}_{2} \text { (acrylamide) } \\
\mathrm{NH}_{2} \mathrm{CN} \text { (cyanamide) } \\
\mathrm{NH}_{2} \mathrm{OH} \text { (hydroxylamine) } \\
\mathrm{NH}_{2} \mathrm{NC} \text { (isocyanamide) } \\
\mathrm{NH}_{2} \mathrm{~F} \text { (monofluoramine) }\end{array}$ & $\begin{array}{l}\text { Nonplanar Equilibrium Structure } \\
\quad-3.9433(9)^{n} \\
-4.0889(29)^{o} \\
-4.147(19)^{p} \\
-4.227(6)^{q} \\
-4.2961(8)^{s} \\
-4.394^{t} \\
-4.6(3)^{u} \\
-4.945(19)^{w} \\
-5.76^{x} \\
-5.764(58)^{y} \\
-6.55^{z}\end{array}$ & $\begin{array}{r}0.130 \\
-0.425 \\
-0.330 \\
-0.411^{r} \\
0.076 \\
-3.959 \\
0.131 \\
0.285 \\
-2.597 \\
-0.752 \\
-1.141\end{array}$ & $\begin{array}{l}\text { planar } \\
\text { nonplanar } \\
\text { nonplanar } \\
\text { nonplanar } \\
\text { planar } \\
\text { nonplanar } \\
\text { planar }^{v} \\
\text { nonplanar } \\
\text { nonplanar } \\
\text { nonplanar } \\
\text { nonplanar }\end{array}$ \\
\hline
\end{tabular}

${ }^{a}$ Vibrational contribution to the inertial defect is calculated by subtracting the equilibrium value, calculated at the VTZ MP2 level, from the ground state value. The reference is the same as for $\chi_{c c}$ (unless otherwise stated). There is no quadrupole data measured for carbamic acid; therefore, CA is not included in the table. ${ }^{b}$ Heavy atom skeleton in the $(a, b)$ symmetry plane. ${ }^{c}$ Vormann, K.; Dreizler, H.; Doose, J.; Guarnieri, A. Z. Naturforsch. 1991, 46A, 770-776. ${ }^{d}$ Vormann, K.; Dreizler, H. Z. Naturforsch. 1991, 46A, 909-913. ${ }^{e}$ Fantoni, A.; Caminati, W.; Hartwig, H.; Stahl, W. J. Mol. Struct. 2002, 612, 305-307. ${ }^{f}$ Aviles Moreno, J.-R.; Huet, T. H.; Petitprez, D. J. Mol. Struct. 2006, 780-781, 234-237. ${ }^{g}$ The large negative value of the inertial defect is explained by large-amplitude low-energy torsion around the $\mathrm{C}-\mathrm{N}$ bond. ${ }^{h} \mathrm{Heineking}$, N.; Dreizler, $\mathrm{H}$. Z. Naturforsch. 1993, 48A, 787-792. ${ }^{i}$ Marstokk, K.-M.; Møllendal, H. J. Mol. Struct. 1974, 22, 287-300. ${ }^{j}$ Reference 4. ${ }^{k}$ Ohashi, N.; Hougen, J. T.; Suenram, R. D.; Lovas, F. J.; Kawashima, Y.; Fujitake, M.; Pyka, J. J. Mol. Spectrosc. 2004, 227, 28-42. ${ }^{l}$ The vibrational contribution to the inertial defect calculated with the aug-cc-pVTZ B3LYP harmonic force field is $0.637 \mathrm{uA}^{2}{ }^{2}{ }^{m}$ Kukolich, S. G.; Nelson, A. C. Chem. Phys. Lett. 1971, 11, 383-384. ${ }^{n}$ Reference 54. ${ }^{\circ}$ Kretschmer, U.; Consalvo, D.; Knaach, A.; Schade, W.; Stahl, W.; Dreizler, H. Mol. Phys. 1996, 87, 11591168. ${ }^{p}$ Brown, R. D.; Godfrey, P. D.; Kleibömer, B. J. Mol. Spectrosc. 1987, 124, 21-33. ${ }^{q}$ Kleibömer, B.; Sutter, D. H. Z. Naturforsch. A 1988, 43, 561-571. ${ }^{r}$ Lister, D. G.; Tyler, J. K.; Høg, J. H.; Larsen, N. W. J. Mol. Struct. 1974, 23, 253-264. ${ }^{s}$ Present work. ${ }^{t}$ Kreglewski, M.; Wlodarczak, G. J. Mol. Spectrosc.1992, 156, 383-389. " Marstokk, K.-M.; Møllendal, H.; Samdal, S. J. Mol. Struct. 2000, 524, 69-85. ${ }^{v}$ The ground-state structure of acrylamide is probably not planar, similarly to MC. ${ }^{w}$ Brown, R. D.; Godfrey, P. D.; Head-Gordon, M.; Wiedenmann, K. H.; Kleibömer, B. J. Mol. Spectrosc. 1988, 130, 213-220. ${ }^{x}$ Morino, I.; Yamada, K. M. T.; Klein, H.; Belov, S. P.; Winnewisser, G.; Bocquet, R.; Wlodarczak, G.; Lodyga, W.; Kreglewski, M. J. Mol. Spectrosc. 2000, 517-518, 367-373. ${ }^{y}$ Schäfer, E.; Winnewisser, M. Ber. Bunsen-Ges. Phys. Chem. 1982, 86, 780-790. ${ }^{z}$ Christen, D.; Minkwitz, R.; Nass, R. J. Am. Chem. Soc. 1987, 109, 7020-7024.

TABLE 8: Comparison between Predicted and Experimental Rotational Constants (in MHz) of Methyl Carbamate

\begin{tabular}{|c|c|c|c|c|c|c|c|c|}
\hline method $^{a}$ & & $A$ & $\Delta A^{b}$ & $B$ & $\Delta B^{b}$ & $C$ & $\Delta C^{b}$ & $\Delta^{c}$ \\
\hline exp. & $v=0$ & 10719.4 & & 4399.1 & & 3182.9 & & 3.247 \\
\hline semiexp. & equil. $^{d}$ & 10801.5 & -0.77 & 4438.7 & -0.90 & 3213.7 & -0.97 & 3.387 \\
\hline ab initio & equil. $^{e}$ & 10707.4 & 0.11 & 4449.1 & -1.14 & 3209.8 & -0.85 & 3.342 \\
\hline CCSD(T) & V(T,D)Z & 10755.2 & -0.33 & 4444.1 & -1.02 & 3212.2 & -0.94 & 3.407 \\
\hline
\end{tabular}

${ }^{a}$ See Table $\mathrm{S} 8$ for a detailed list of computed results. ${ }^{b} \Delta A=A_{0}-A_{\text {calc.; }} ; \Delta B=B_{0}-B_{\text {calc.; }} ; \Delta C=C_{0}-C_{\text {calc, }}$, all in $\%$. ${ }^{c} \Delta=I_{a}+I_{b}-I_{c}$ (in $\mathrm{u}^{2}{ }^{2}$ ). ${ }^{d}$ Semiexperimental value of the equilibrium rotational constants, calculated employing the measured ground-state rotational constants and vibrational averaging corrections computed at the all-electron 6-31G* MP2 level. ${ }^{e}$ From last column of Table $6 .{ }^{f}$ Planar heavy-atom skeleton $\left(C_{s}\right.$ point-group symmetry).

TABLE 9: Computed Equilibrium and Experimental Ground-State Dipole Moment Components (in Debye) of Methyl Carbamate ${ }^{a}$

\begin{tabular}{llllll}
\hline \multicolumn{1}{c}{ method } & & \multicolumn{1}{c}{$\mu_{a}$} & \multicolumn{1}{c}{$\mu_{b}$} & \multicolumn{1}{c}{$\mu_{c}$} & \multicolumn{1}{c}{$\mu_{\text {tot }}$} \\
\hline exp. & & $0.163(2)$ & $2.294(9)$ & $0^{\mathrm{c}}$ & $2.300(9)$ \\
CCSD(T) & V(T,D)Z & 0.234 & 2.215 & 0.710 & 2.338 \\
CCSD(T) & V(T,D)Z & 0.435 & 2.354 & 0.0 & 2.394
\end{tabular}

${ }^{a}$ All electrons have been correlated in the computations. ${ }^{b}$ Obtained at the optimized structure under the constraint of a planar heavy-atom skeleton. ${ }^{c}$ The fit performed as part of this study results in $\left(\mu_{\mathrm{c}}\right)^{2}=$ $-0.001 .{ }^{d}$ The corresponding vibrationally averaged ground-state value, based on a normal-coordinate expansion, is $0.573 \mathrm{D}$, significantly lower than the equilibrium value but still far from zero.

was not planar, the $\mu_{c}$ component of the dipole moment would be different from zero (Table 9). With a value even as small as $0.1 \mathrm{D}$, note that the ab initio values are much larger, $c$-type transitions should be easily detected with the highly sensitive technique of MWFT. We used a pulsed-nozzle MWFT spectrometer $^{70}$ to search for such transitions and could not detect any. This clearly confirms that the vibrationally averaged $\mu_{c}$ component of the dipole moment is very close to zero. This is the most convincing experimental evidence for the planarity of the amide linkage of MC in the ground state.

In conclusion, the picture of MC having a nonplanar equilibrium structure deduced from high-level ab initio calculations and a planar ground-state structure deduced from experiments can be understood as follows. MC behaves as urea and many other molecules containing the amino group, whereby "the two shapes (planar and nonplanar) are likely to be parts of a potential energy surface domain which is associated with the most stable shape, i.e., one in which the zero-point vibration 
TABLE 10: Barrier to Internal Rotation of the Methyl Group (in $\mathrm{cm}^{-1}$ ) in Methyl Carbamate from Experimental Measurements and from ab Initio Computations ${ }^{a}$

\begin{tabular}{llr}
\hline & \multicolumn{1}{c}{$V_{3}$} & exp. - calc./\% \\
\hline exp. & $352.42(8)^{b}$ & \\
6-311+G(3df,2p) MP2_AE & 366.2 & -4 \\
6-31G(d) MP2_AE & 283.0 & 20 \\
G3 & 396.9 & -13 \\
VTZ B3LYP & 203.5 & 42 \\
CCSD(T) & 327.8 & 7
\end{tabular}

${ }^{a}$ The calculated values, except $\operatorname{CCSD}(\mathrm{T})$, take into account the same ZPE correction of $-5.0 \mathrm{~cm}^{-1}$, computed at the 6-31G* B3LYP level. ${ }^{b}$ The original value of $V_{3}\left(352.2 \mathrm{~cm}^{-1}\right)$ reported in ref 9 was refined in the present work using the so-called RAM approach (see also ref 53 and references in it). Both potential barrier height determinations involved $V_{6}=V_{9}=0 .{ }^{c}$ See text for details.

TABLE 11: Observed and Computed Quartic Centrifugal Distortion Constants, in $\mathrm{kHz}$, for MC

\begin{tabular}{llcccc}
\hline & \multicolumn{1}{c}{ exp. $^{9, a}$} & calc.(I) $^{b}$ & IR contr. $^{c}$ & calc.(II) $^{a, d}$ & $\begin{array}{c}\text { exp. }- \text { calc.(II) } \\
(\%)\end{array}$ \\
\hline$\Delta_{J}$ & $0.7794(7)$ & 0.7574 & 0.0032 & 0.7606 & 2.4 \\
$\Delta_{J K}$ & $4.5326(29)$ & 4.6700 & 0.5684 & 5.2385 & -15.6 \\
$\Delta_{K}$ & $8.9474(22)$ & 3.9092 & 5.2117 & 9.1209 & -1.9 \\
$\delta_{J}$ & $0.2164(3)$ & 0.2040 & 0.0016 & 0.2056 & 5.0 \\
$\delta_{K}$ & $2.4033(33)$ & 2.1777 & 0.3057 & 2.4835 & -3.3
\end{tabular}

${ }^{a}$ For the $A$ component of the internal rotation doublet. ${ }^{b}$ "Unperturbed" constants obtained at the VTZ B3LYP level. The corresponding 6-31G* MP2 values are 0.7273, 4.0974, 3.4937, 0.2079, and 2.2731. ${ }^{c}$ Contribution of the internal rotation (IR). Calculated with $F=167.26$ $\mathrm{GHz}, s=28$, and $\lambda_{\mathrm{a}}=0.9137 .{ }^{d}{ }^{d}$ Sum of the unperturbed value, given under column calc. (I), and the internal rotation contribution, given under IR contr.

covers both geometries". ${ }^{71}$ In other words, the ground-state energy level corresponding to the one-dimensional effective inversion motion lies above the top of the barrier separating the planar and the nonplanar forms explaining why the measured out-of-plane electric dipole moment is averaged to zero. In order to provide further confirmation and determine the shape of the potential, it would be necessary to measure excited vibrational states. However, as the spectrum is extremely crowded, this appears to be a daunting task.

3.6.3. Barrier to Internal Rotation of the Methyl Group. The theory of internal rotation involves many parameters which can make their experimental determination somewhat difficult. These parameters, at least in principle, can be obtained ab initio. The main difficulty is to achieve an accuracy for relative energies to the level of about a few $\mathrm{cm}^{-1}$. However, very accurate computations have recently been performed for a few small molecules, like acetaldehyde. ${ }^{15}$

Here we wish to check whether it is possible to calculate ab initio an accurate potential curve and barrier for the methyl internal rotation of $\mathrm{MC}$ at a reasonable cost.

The barrier was first calculated at the all-electron $6-311+\mathrm{G}-$ (3df,2p) MP2 level of theory in the same way as for methanol and acetaldehyde. ${ }^{72}$ The zero-point energy (ZPE) corrections arising from the complementary, nontorsional modes have been calculated at the 6-31G* HF level, including scaling, as in the Gaussian-3 (G3) method. ${ }^{73}$ The result is given in Table 10 and is in satisfactory agreement with the experimental value, the deviation being only $4 \%$. However, this agreement might be accidental because the basis set used is small. Furthermore, it is not obvious that the MP2 method is sufficient for recovering correlation effects. The energy difference at the $6-31 \mathrm{G}^{*} \mathrm{MP} 2$ level, $283.0 \mathrm{~cm}^{-1}$, is close to the value found at the $6-31 \mathrm{G}^{*}$ QCISD(T) level, $284.5 \mathrm{~cm}^{-1}$, confirming that most of the correlation is recovered at the MP2 level (although the 6-31G* basis set might be too small to obtain dependable results ${ }^{15}$ ).

To get more insight into the internal rotation of the methyl group in MC, we computed the energy differences between the conformers using G3 theory. ${ }^{73}$ The ZPE corrections were first calculated at the $6-31 \mathrm{G}^{*} \mathrm{HF}$ level, followed by a scaling of the vibrational frequencies with a scale factor of 0.8929 . G3 theory uses, as reference geometry, the geometry from an all-electron 6-31G* MP2 optimization. The computed barrier at the G3 level is $V_{3}=396.9 \mathrm{~cm}^{-1}$, compared to an experimental value of $352.42(8) \mathrm{cm}^{-1}$. The difference is almost $13 \%$.

In order to obtain a reliable internal rotation curve and an associated barrier for the methyl torsion, we used a local version of the ACESII electronic structure package ${ }^{33 b}$ to optimize the structure of MC while keeping the torsional coordinate $\tau$, defined as $\tau=1 / 3\left(\rho_{1}+\rho_{2}+\rho_{3}-2 \pi\right),{ }^{14}$ where $\rho_{i}$ are the dihedral angles $\mathrm{H}_{i} \mathrm{COC}$, fixed at values very near to $0^{\circ}, 15^{\circ}, 30^{\circ}, 45^{\circ}$, and $60^{\circ}$. The $2 \pi / 3$-periodic internal rotation potential of $\mathrm{MC}$ is an even function and thus this region completely determines the shape of the torsional potential. The constrained optimizations have been performed at the all-electron $\mathrm{V}(\mathrm{T}, \mathrm{D}) \mathrm{Z}$ $\operatorname{CCSD}(T)$ level. Single-point energies at the all-electron cc-pCVTZ CCSD(T) level have been computed at the optimized reference structures. These energy values were fitted to the functional form

$$
\begin{gathered}
V(\tau)=1 / 3\left[V_{3}(1-\cos (3 \tau))+V_{6}(1-\cos (6 \tau))+\right. \\
\left.V_{9}(1-\cos (9 \tau))\right]
\end{gathered}
$$

The fitted $\left\{V_{3}, V_{6}, V_{9}\right\}$ values are, in $\mathrm{cm}^{-1},\{328.3,-20.3$, $+1.6\}$. These values do not reflect the effect of zero-point vibrational energy corrections arising from the complementary, nontorsional modes.

Finally, it is noted that a fit of the available experimental data set ${ }^{8,9}$ to an internal rotation Hamiltonian with a fixed value of $V_{6}$ of $-20.3 \mathrm{~cm}^{-1}$ and $V_{9}$ of $+1.6 \mathrm{~cm}^{-1}$ gave about the same standard deviation as the fit with $V_{6}=V_{9}=0$ and the experimentally determined values of $V_{3}$ in the two cases differed by only $4 \%$, a result which is expected when dealing with experimental data from the ground torsional state $v_{\mathrm{t}}=0$.

3.6.4. Harmonic Force Field and Quartic Centrifugal Distortion Constants. It is generally accepted that for most organic molecules the ab initio HF and especially the density-functional B3LYP methods, with small to medium-sized basis sets, give reliable harmonic force fields (HFF) at moderate cost. ${ }^{74-77}$ The HFF of MC has been calculated at the 6-31G* HF, VTZ, and AVTZ B3LYP levels. The complete quartic force field of MC has been computed at the all-electron 6-31G* MP2 level resulting in harmonic as well as anharmonic vibrational fundamentals. The calculated fundamentals are compared to the observed ones ${ }^{78,79}$ in Table S17. When the computed frequencies are scaled using recommended scale factors, 0.8929 for $6-31 \mathrm{G}^{*}$ $\mathrm{HF},{ }^{80} 0.965$ for $\mathrm{CH}$ stre, and 0.975 for all other modes for VTZ B3LYP, ${ }^{81}$ the agreement between theory and experiment becomes satisfactory.

The equilibrium quartic centrifugal distortion (QCD) constants have been calculated from the VTZ B3LYP force field without scaling (the AVTZ B3LYP method gives almost identical results) and the 6-31G* MP2 force field. The calculated equilibrium constants are compared to the experimental groundstate values in Table 11. At first sight, the agreement appears to be unsatisfactory. Nevertheless, one has to note that the experimental values have been determined for the $A$-component of the internal-rotation doublets whereas the calculated values 
TABLE 12: Observed and Calculated ${ }^{14} \mathrm{~N}$ Nuclear Quadrupole Coupling Constants (in MHz) for Formamide ${ }^{a}$

\begin{tabular}{lllcrrrr}
\hline method & & $\chi_{a a}$ & $\mathrm{e}-\mathrm{c}(a a) / \%$ & $\chi_{b b}$ & $\mathrm{e}-\mathrm{c}(b b) / \%$ & $\chi_{\mathrm{cc}}$ & $\mathrm{e}-\mathrm{c}(c c) / \%$ \\
\hline exp. $^{b}$ & & $1.960(2)$ & & $1.888(3)$ & & $-3.848(4)$ & -3.495 \\
HF & VTZ & 1.767 & 9.85 & 1.728 & 8.47 & -3.348 & 9.17 \\
& AVTZ & 1.703 & 13.11 & 1.646 & 12.82 & -3.494 & 9.20 \\
& VQZ & 1.762 & 10.10 & 1.733 & 18.64 & -3.128 & 18.71 \\
MP2 & VTZ & 1.592 & 18.78 & 1.536 & 14.41 & -3.278 & 14.81 \\
B3LYP & VTZ & 1.662 & 15.20 & 1.616 & 20.34 & -3.085 & 19.83
\end{tabular}

${ }^{a} \mathrm{e}=$ experimental, $\mathrm{c}=$ computed. ${ }^{b}$ Reference 84.

TABLE 13: Observed and Calculated ${ }^{14} \mathbf{N}$ Nuclear Quadrupole Coupling Constants (MHz) for Methyl Carbamate $^{a}$

\begin{tabular}{|c|c|c|c|c|c|c|}
\hline & \multirow[b]{2}{*}{$\exp .(\mathrm{I})^{b}$} & \multirow[b]{2}{*}{$\exp .(\mathrm{II})^{c}$} & \multicolumn{2}{|c|}{ VTZ HF } & \multicolumn{2}{|c|}{ AVTZ B3LYP } \\
\hline & & & calc. & $\begin{array}{c}{[\mathrm{e}(\mathrm{II})-\mathrm{c}] /} \\
\%\end{array}$ & calc. & $\begin{array}{c}{[\mathrm{e}(\mathrm{II})-\mathrm{c}] /} \\
\%\end{array}$ \\
\hline$\overline{e Q q_{a a}}$ & $1.52(27)$ & $2.2833(7)$ & 1.99 & 12.8 & 1.85 & 18.9 \\
\hline$e Q q_{b b}$ & $3.51(20)$ & $2.0128(8)$ & 1.82 & 9.5 & 1.68 & 16.4 \\
\hline$e Q Q q_{c c}$ & $-5.03(33)$ & $-4.2961(8)$ & -3.81 & 11.3 & -3.54 & 17.7 \\
\hline
\end{tabular}

refer to the unperturbed frequencies. Taking into account the internal-rotation correction ${ }^{82}$ improves the agreement considerably. At $57 \%$, the internal rotation contribution is particularly large for the $\Delta_{K}$ constant. The computed $\Delta_{J K}$ constant is significantly too large, by $15.6 \%$, at the VTZ B3LYP level but it has to be remembered that lower-level force fields do have certain deficiencies. For instance, if the VTZ B3LYP force field is recomputed assuming a planar heavy-atoms skeleton, the $\Delta_{J K}$ constant is decreased by $2 \mathrm{kHz}$ and becomes too small (the variation of the other constants is much smaller). However, despite this apparent deficiency, the ab initio prediction of the QCD constants from a medium-quality harmonic force field is, as usual, ${ }^{83}$ accurate enough to help in the analysis of the rotational spectrum.

3.6.5. Quadrupole Coupling Constants. In order to choose a level of theory appropriate to compute the quadrupole coupling (QC) constants of nitrogen, we first calculated the QC constants of formamide. The reference geometry employed is the $r_{\mathrm{e}}^{\mathrm{BO}}$ estimate of Table 1. The resulting QC constants are presented in Table 12. It appears that the VTZ HF method gives a QCs closest to that of the experiment. ${ }^{84}$ Although this is probably due to compensation of errors, we employed the same level for MC. As a check, the calculation was repeated at the AVTZ B3LYP level. The results for MC are given in Table 13. The agreement between the observed and computed constants of $\mathrm{MC}$ is far from being perfect, the deviations are systematic and of the same order of magnitude as for formamide. Nevertheless, the accuracy of the predicted constants is good enough to start the analysis of the hyperfine structure of the rotational lines. It must also be remembered that it is not easy to obtain the experimental quadrupole coupling constants with high accuracy, as the results corresponding to two independent experimental determinations presented in Table 13 imply.

3.7. CO Bond Lengths. Equilibrium $\mathrm{C}=\mathrm{O}$ bond lengths, $r_{\mathrm{e}}(\mathrm{C}=\mathrm{O})$, are known for several molecules. The results are collected in Table 14 together with the corresponding frozencore VQZ MP2 $r_{\mathrm{e}}$ values. As expected, there is good correlation, $\rho=0.999$, between the two sets of values (Figure 2). However, the offset $\Delta r=r_{\mathrm{e}}-r$ [VQZ MP2] does not appear to be constant. Nevertheless, the variation of $\Delta r$ as a function of $r_{\mathrm{e}}(\mathrm{C}=\mathrm{O})$ is nearly linear between $1.160 \AA, r_{\mathrm{e}}$ in $\mathrm{CO}_{2}$, and 1.211 $\AA, r_{\mathrm{e}}$ in $\mathrm{HC}(\mathrm{O}) \mathrm{NH}_{2}$, making the estimation of the offset straightforward. It has to be noted that for OCS and OCSe, with
TABLE 14: Comparison of Equilibrium and cc-pVQZ MP2 Bond Lengths for $\mathrm{C}=\mathrm{O}$ (in $\AA$ )

\begin{tabular}{|c|c|c|c|}
\hline molecule $^{a}$ & $r_{\mathrm{e}}$ & VQZ MP2 & offset $\left(r_{\mathrm{e}}-\mathrm{VQZ}\right.$ MP2) \\
\hline \multicolumn{4}{|c|}{$\mathrm{C}=\mathrm{O}$ Bond } \\
\hline OCSe & $1.1533^{b}$ & 1.1640 & -0.011 \\
\hline OCS & $1.1562^{c}$ & 1.1651 & -0.0089 \\
\hline $\mathrm{CO}_{2}$ & $1.1600^{d}$ & 1.1662 & -0.0062 \\
\hline $\mathrm{H}_{2} \mathrm{CCO}$ & $1.1603^{e}$ & 1.1643 & -0.0040 \\
\hline $\mathrm{HNCO}$ & $1.1641^{f}$ & 1.1696 & -0.0055 \\
\hline $\mathrm{OCFCl}$ & $1.1730^{g}$ & 1.1775 & -0.0045 \\
\hline OCHF & $1.1773^{h}$ & 1.1812 & -0.0039 \\
\hline $\mathrm{OCHCl}$ & $1.1820^{i}$ & 1.1862 & -0.0042 \\
\hline $\mathrm{HCOOH}$ cis & $1.1910^{j}$ & 1.1945 & -0.0035 \\
\hline $\mathrm{HCOOH}$ trans & $1.1974^{k}$ & 1.2010 & -0.0036 \\
\hline $\mathrm{HCOCOOH}$ & $1.1977^{k}$ & 1.2025 & -0.0048 \\
\hline azetidinone & $1.201^{l}$ & 1.2044 & -0.0034 \\
\hline $\mathrm{H}_{2} \mathrm{CO}$ & $1.2047^{m}$ & 1.2082 & -0.0035 \\
\hline $\mathrm{HC}(\mathrm{O}) \mathrm{NH}_{2}$ & $1.2109^{j}$ & 1.2132 & -0.0023 \\
\hline $\mathrm{OC}\left(\mathrm{NH}_{2}\right)$ & $1.2116^{j}$ & 1.2148 & -0.0032 \\
\hline $\mathrm{C}(\mathrm{O}) \mathrm{HCH}_{2} \mathrm{OH}$ & $1.2082^{j}$ & 1.2125 & -0.0043 \\
\hline $\mathrm{HCOCOOH}$ & $1.2087^{k}$ & 1.2114 & -0.0027 \\
\hline \multicolumn{4}{|c|}{$\mathrm{C}-\mathrm{O}$ Bond } \\
\hline $\mathrm{HOCN}$ & $1.3008^{j}$ & 1.2995 & +0.0013 \\
\hline $\mathrm{HC}(\mathrm{O}) \mathrm{COOH}$ & $1.3317^{k}$ & 1.3322 & -0.0005 \\
\hline $\mathrm{HCOOH}$ trans & $1.3410^{k}$ & 1.3427 & -0.0017 \\
\hline $\mathrm{HCOOH}$ cis & $1.3472^{j}$ & 1.3493 & -0.0021 \\
\hline $\mathrm{CH}_{2}=\mathrm{CHOH}$ & $1.3593^{j}$ & 1.3582 & +0.0011 \\
\hline $\mathrm{C}(\mathrm{O}) \mathrm{HCH}_{2} \mathrm{OH}$ & $1.3956^{j}$ & 1.3960 & -0.0004 \\
\hline$\left(\mathrm{CH}_{3}\right)_{2} \mathrm{O}$ & $1.4062^{j}$ & 1.4066 & -0.0004 \\
\hline $\mathrm{CH}_{3} \mathrm{OH}$ & $1.4171^{j}$ & 1.4174 & -0.0003 \\
\hline $\mathrm{CH}_{3} \mathrm{CH}_{2} \mathrm{OH}$ trans & $1.4215^{j}$ & 1.4226 & -0.0011 \\
\hline$c-\mathrm{C}_{2} \mathrm{H}_{4} \mathrm{O}$ & $1.4256^{n}$ & 1.4303 & -0.0047 \\
\hline
\end{tabular}

${ }^{a}$ References for $r_{\mathrm{e}}$ structures are given explicitly; the VQZ MP2 bond lengths have been computed as part of this study. ${ }^{b}$ Le Guennec, M.; Wlodarczak, G.; Demaison, J.; Bürger, H.; Litz, M.; Willner, H. J. Mol. Spectrosc. 1993, 157, 419-446. ${ }^{c}$ Lahaye, J. G.; Vandenhaute, R.; Fayt, A. J. Mol. Spectrosc. 1987, 123, 48-83. ${ }^{d}$ Graner, G.; Rossetti, C.; Bailly, D. Mol. Phys. 1986, 58, 627-636. ${ }^{e}$ East, A. L. L.; Allen, W. D.; Klippenstein, S. J. J. Chem. Phys. 1995, 102, 8506-8532. The frozen-core VDZ, VTZ, VQZ, and CBS CCSD(T) $\mathrm{C}=\mathrm{O}$ bond lengths in ketene are $1.1763,1.1670,1.1632$, and $1.1606 \AA$, in order, computed as part of this study. A related core correction is $-0.0022 \AA$, resulting in an $r_{\mathrm{e}}=1.1584 \AA$. These optimization results might explain why the offset value of ketene is so different from molecules with a similar $\mathrm{C}=\mathrm{O}$ bond length. ${ }^{f}$ Reference 38. ${ }^{g}$ Demaison, J.; Perrin, A.; Bürger, H. J. Mol. Spectrosc. 2003, 221, 47-56. ${ }^{h}$ Margulès, L.; Demaison, J.; Boggs, J. E. J. Phys. Chem. A 1999, 103, 7632-7638. ${ }^{i}$ Demaison, J.; Boggs, J. E.; Rudolph, H. D. J. Mol. Struct. 2004, 695-696, 145153. ${ }^{j}$ This work. ${ }^{k}$ Reference $85 .{ }^{l}$ Demyk, K.; Petitprez, D.; Demaison, J.; Møllendal, H.; Wlodarczak, G. Phys. Chem. Chem. Phys. 2003, 5, 5038-5043. ${ }^{m}$ Pawlowski, F.; Jørgensen, P.; Olsen, J.; Hegelund, F.; Helgaker, T.; Gauss, J.; Bak, K. L.; Stanton, J. F. J. Chem. Phys. 2002, 116, 6482-6496. ${ }^{n}$ Reference 39.

bond lengths shorter than in $\mathrm{CO}_{2}$, the linear correlation breaks down. We did not find any satisfactory explanation for this behavior.

The situation is considerably less favorable for the $\mathrm{C}-\mathrm{O}$ single bond lengths. Equilibrium values have been known in oxirane, $c-\mathrm{C}_{2} \mathrm{H}_{4} \mathrm{O},{ }^{38}$ which is a ring, in formic acid, $\mathrm{HCOOH},{ }^{85}$ 


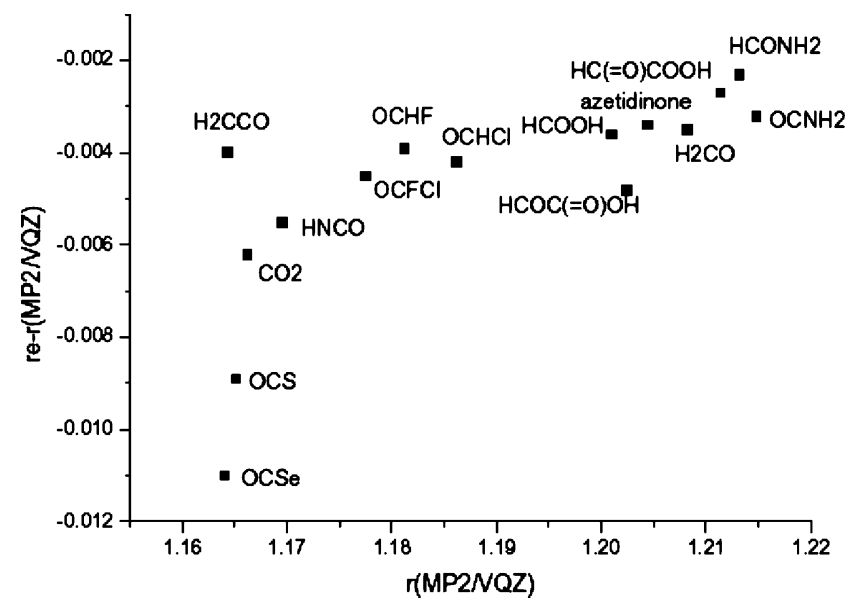

Figure 2. Plot of $r_{\mathrm{e}}-r$ [VQZ MP2] as a function of $r_{\mathrm{e}}$ for the $\mathrm{C}=\mathrm{O}$ bond length (in $\AA$ ).

and in glyoxylic acid, $\mathrm{HC}(\mathrm{O}) \mathrm{COOH},{ }^{85}$ where the $\mathrm{C}-\mathrm{O}-\mathrm{H}$ moiety is involved instead of $\mathrm{C}-\mathrm{O}-\mathrm{C}$, as in $\mathrm{MC}$ (Table 14). For this reason, we have computed the structure of dimethylether, $\left(\mathrm{CH}_{3}\right)_{2} \mathrm{O}$, where the $\mathrm{C}-\mathrm{O}-\mathrm{C}$ moiety is present, and that of a few other molecules (Table 14). Structural results for $\left(\mathrm{CH}_{3}\right)_{2} \mathrm{O}$, obtained at several levels of theory, are reported in Table S18. The effect of diffuse functions on the $\mathrm{C}-\mathrm{O}$ bond length is still large at the VQZ level, the increase in the bond length is $0.002 \AA$. An empirical three-parameter exponential formula, $r(n)=r(\infty)+b \mathrm{e}^{-c n}$, was used to extrapolate the $\mathrm{AV} n \mathrm{Z}$ $\operatorname{CCSD}(\mathrm{T})$ values with $n=\mathrm{D}, \mathrm{T}, \mathrm{Q}$, to the CBS limit. This extrapolation gives $1.4089 \AA$ for $r_{\mathrm{e}}(\mathrm{C}-\mathrm{O})$, which is in excellent agreement with the V5Z CCSD(T) $r_{\mathrm{e}}$ value, $1.4090 \AA$. In other words, at the V5Z level, there is no need to take into account the effect of diffuse functions.

The experimental $r_{\mathrm{m}}^{(2)}$ structure ${ }^{44}$ has also been calculated for dimethylether (Table S18). As to the CO bond length, it is in good agreement with the ab initio value. It has to be noted that the $r_{\mathrm{s}}$ structure $^{86}$ is also close to the ab initio $r_{\mathrm{e}}$ structure.

The few $r_{\mathrm{e}}(\mathrm{C}-\mathrm{O})$ data available, see Table 14, indicate that the VQZ MP2 value is close, within $0.003 \AA$, to the equilibrium value which has been determined either experimentally or using high-level ab initio electronic structure calculations.

3.8. CN Bond Lengths. The equilibrium $\mathrm{C}-\mathrm{N}$ bond lengths of several molecules have been determined during this study. Furthermore, additional equilibrium values are known from the literature. All of these values are reported in Table 15. The $\mathrm{C} \equiv \mathrm{N}$ bond lengths are not considered because they have been recently reviewed. ${ }^{87}$ It is known that a constant offset may be used to correct the MP2 values, and their behavior is different from the $\mathrm{C}-\mathrm{N}$ bond lengths.

During compilation of the results, it occurred to us that no high-accuracy computed equilibrium structure for the simplest molecule with a pure single $\mathrm{C}-\mathrm{N}$ bond, i.e., $\mathrm{CH}_{3} \mathrm{NH}_{2}$ (methylamine), has been reported. Therefore, we have computed the equilibrium structure of methylamine at the all-electron VQZ $\operatorname{CCSD}(\mathrm{T})$ level. This structure is expected to be close to the true equilibrium structure. ${ }^{35}$ Particularly, it has been checked that the $\operatorname{CCSD}(\mathrm{T})$ structure computed at the VQZ level appears to be close to the CBS limit, since the cc-pwCVQZ and ccpVQZ basis sets give identical results at the all-electron MP2 level. The computed structure is given in Table 16 .

The experimental structure of $\mathrm{CH}_{3} \mathrm{NH}_{2}$ has been determined several times, either from ground-state rotational constants ${ }^{88,89}$ or by gas electron diffraction (GED). ${ }^{90}$ However, all of these structural studies assumed that the methyl group is symmetric,
TABLE 15: Comparison of Equilibrium and Frozen-Core VQZ MP2 Bond Lengths for the CN Bond in Different Molecules (in $\AA)^{a}$

\begin{tabular}{lccc}
\hline \multicolumn{1}{c}{ molecule } & $r_{\mathrm{e}}$ & VQZ MP2 & offset $\left(r_{\mathrm{e}}-\right.$ VQZ MP2 $)$ \\
\hline & & $\mathrm{C}=\mathrm{N}$ bond & \\
$\mathrm{HN}=\mathrm{C}=\mathrm{O}$ & $1.215^{b}$ & 1.217 & -0.002 \\
$\mathrm{HNCNH}$ & $1.222^{c}$ & 1.225 & -0.003 \\
$\mathrm{~F}_{2} \mathrm{C}=\mathrm{NH}$ & $1.239^{d}$ & 1.242 & -0.003 \\
$\mathrm{H}_{2} \mathrm{C}=\mathrm{NH}$ & $1.271^{e}$ & 1.273 & -0.002 \\
& & $\mathrm{C}-\mathrm{N}$ bond \\
$\mathrm{H}_{2} \mathrm{~N}-\mathrm{CN}$ & $1.348^{f}$ & 1.347 & 0.001 \\
$\mathrm{HC}(\mathrm{O}) \mathrm{NH}_{2}$ & $1.355^{f}$ & 1.355 & 0.000 \\
$\mathrm{H}_{2} \mathrm{NCOOH}$ & $1.358^{f}$ & 1.356 & 0.002 \\
$\mathrm{MC}$ & $1.362^{f}$ & 1.362 & 0.000 \\
$\mathrm{OC}\left(\mathrm{NH}_{2}\right)_{2}$ & $1.382^{f}$ & 1.381 & 0.001 \\
$\mathrm{CH} \mathrm{NC}_{3}$ & $1.422^{g}$ & 1.418 & 0.004 \\
glycine-Ip & $1.441^{h}$ & 1.443 & -0.002 \\
$\mathrm{CH} \mathrm{NH}_{2}$ & $1.461^{f}$ & 1.460 & 0.001 \\
proline-I & $1.473^{i}$ & 1.475 & -0.002
\end{tabular}

${ }^{a} \mathrm{VQZ}$ CCSD(T) + cc-pwCVQZ [MP2_AE - MP2_FC]. ${ }^{b}$ Reference 38. ${ }^{c}$ Koput, J.; Jabs, W.; Winn, M. Chem. Phys. Lett. 1998, 295, 462-466. ${ }^{d}$ Puzzarini, C.; Gambi, A. J. Phys. Chem. A 2004, 108, 4138-4145. ${ }^{e}$ Margulés, L.; Demaison, J.; Sreeja, P. B.; Guillemin, J. C. J. Mol. Spectrosc. 2006, 238, 234-240. ${ }^{f}$ This work. ${ }^{g}$ Reference 29. ${ }^{h}$ Reference 13. ${ }^{i}$ Allen, W. D.; Czinki, E.; Császár, A. G. Chem. Eur. J. 2004, 10, 4512-4517.

TABLE 16: Equilibrium Structure of Methylamine, $\mathrm{CH}_{3} \mathrm{NH}_{2}$, Calculated at the All-Electron VQZ CCSD(T) Level (Distances in $\AA$ and Angles in Degree) ${ }^{a}$

\begin{tabular}{lclr}
\hline parameter & value & parameter & value \\
\hline$r(\mathrm{~N}-\mathrm{H})$ & 1.0096 & $\angle\left(\mathrm{NCH}_{\mathrm{a}}\right)$ & 109.14 \\
$r(\mathrm{C}-\mathrm{N})$ & 1.4609 & $\angle\left(\mathrm{NCH}_{\mathrm{s}}\right)$ & 114.95 \\
$r\left(\mathrm{C}-\mathrm{H}_{\mathrm{a}}\right)$ & 1.0873 & $\angle\left(\mathrm{H}_{\mathrm{a}} \mathrm{CH}_{\mathrm{a}}\right)$ & 107.21 \\
$r\left(\mathrm{C}-\mathrm{H}_{\mathrm{s}}\right)$ & 1.0932 & $\angle\left(\mathrm{H}_{\mathrm{a}} \mathrm{CH}_{\mathrm{s}}\right)$ & 108.06 \\
$\angle(\mathrm{HNH})$ & 106.08 & $\angle\left(\mathrm{H}^{\prime} \mathrm{NCH}_{\mathrm{a}}\right)$ & 63.34 \\
$\angle(\mathrm{HNC})$ & 109.95 & $\angle\left(\mathrm{HNCH}_{\mathrm{a}}\right)$ & 179.79 \\
& & $\angle\left(\mathrm{HNCH}_{\mathrm{s}}\right)$ & 58.22
\end{tabular}

a $\angle\left(\mathrm{H}^{\prime} \mathrm{NCH}_{a^{\prime}}\right)=-\angle\left(\mathrm{HNCH}_{a}\right), \angle\left(\mathrm{H}^{\prime} \mathrm{NCH}_{s}\right)=-\angle\left(\mathrm{HNCH}_{s}\right)$, and $\angle\left(\mathrm{HNCH}_{a^{\prime}}\right)=-\angle\left(\mathrm{H}^{\prime} \mathrm{NCH}_{a}\right)$. For a planar molecule, $2 \angle \mathrm{HNC}+\angle \mathrm{HNH}$ should be $360^{\circ}$, but in the present case, it is only $326.0^{\circ}$.

which is far from being true. The isolated $\mathrm{C}-\mathrm{H}$ stretching frequencies were used to check the reliability of the ab initio structure of the methyl group : $v\left(\mathrm{CH}_{a}\right)=2955 \mathrm{~cm}^{-1}$ and $v\left(\mathrm{CH}_{s}\right)=2880 \mathrm{~cm}^{-1} \cdot{ }^{91}$ These vibrations correspond to ${ }^{92}$ $r_{\mathrm{e}}\left(\mathrm{CH}_{a}\right)=1.089(2) \AA$ and $r_{\mathrm{e}}\left(\mathrm{CH}_{s}\right)=1.094(2) \AA$, in good agreement with the ab initio structure. There is another problem with the experimental structures, they all give (or assume) $r(\mathrm{C}-\mathrm{N}) \approx 1.471 \AA$, which is considerably longer than the ab initio value, $1.461 \AA$. The rotational constants calculated with the $a b$ initio equilibrium structure are $1.2-1.3 \%$ larger than the corresponding experimental ground-state values. These differences have the right order of magnitude for such a light and non-rigid molecule as $\mathrm{CH}_{3} \mathrm{NH}_{2}$. Our conclusion is that for $\mathrm{CH}_{3}-$ $\mathrm{NH}_{2}$ the ab initio structure is more reliable than the presently available experimental ones.

The residuals $r_{\mathrm{e}}(\mathrm{CN})-r_{\mathrm{cc}-\mathrm{pVQZ}} \mathrm{MP} 2(\mathrm{CN})$ are given in Table 15. For the four molecules with a $\mathrm{C}=\mathrm{N}$ bond $-\mathrm{HNCO}, \mathrm{HNCNH}$, $\mathrm{CF}_{2} \mathrm{NH}$, and $\mathrm{CH}_{2} \mathrm{NH}-$ the bond lengths are quite similar. For the single bond $\mathrm{C}-\mathrm{N}$, the residuals are more dispersed, but assuming an experimental accuracy of $\pm 0.002 \AA$, it may be concluded that the residuals are not significantly different from zero.

It is tempting to try to find a correlation between the $\mathrm{C}-\mathrm{N}$ bond length and the planarity of the CNXY group. The CN bond length is indeed significantly larger for most nonplanar molecules. For instance, at the frozen-core VQZ MP2 level, 
the $\mathrm{CN}$ bond length in nonplanar urea is $1.381 \AA$, much larger than in planar formamide, where it is $1.355 \AA$. However, there are a few exceptions. In carbamic acid (Table 5), the $\mathrm{CN}$ bond length is quite short, although the molecule has a nonplanar equilibrium structure. Nevertheless, in this case, the energy difference between the planar and nonplanar forms is quite small.

\section{Conclusions}

We have addressed a number of issues, both experimental and theoretical, connected with the equilibrium vs ground-state planarity of the $\mathrm{C}(\mathrm{O}) \mathrm{NH}$ linkage in simple biomimetic molecules.

We investigated formamide, the simplest among $\mathrm{XC}(=\mathrm{O}) \mathrm{NHY}$ species with $\mathrm{X}=\mathrm{Y}=\mathrm{H}$. It has a planar ( $C_{s}$ point-group symmetry) equilibrium structure, consistent both with available spectroscopic information and high-quality electronic structure calculations. An almost ultimate representation of $r_{\mathrm{e}}^{\mathrm{BO}}$ of formamide has been obtained. A relatively low level of electronic structure theory which reliably provides a planar structure for formamide turned out to be all-electron cc-pV(T,D)Z CCSD(T), which was then used for most of the other molecules of this study to obtain equilibrium structural information. Formamide does not appear to be a good model of all amide linkages as it exhibits a single-minimum inversion potential, i.e., planar equilibrium and ground-state structures, which appears to be rare among the $\mathrm{XC}(=\mathrm{O}) \mathrm{NHY}$ species.

A number of molecules having the $\mathrm{XC}(=\mathrm{O}) \mathrm{NHY}$ linkage were investigated by sophisticated electronic structure techniques resulting in accurate representations of their equilibrium structures. These include methyl carbamate, cyanamide, acetamide, urea, and carbamic acid. They all have a pyramidalized nitrogen at equilibrium.

An important result of this study is that the ground-state inertial defect is not a good measure of planarity of the $\mathrm{CONH}$ linkage because the vibrational contributions can be extremely large. Other spectroscopic parameters show even more ambiguity while deciding about planarity. If the quadrupole coupling constant $\left|\chi_{c c}\right|\left({ }^{14} \mathrm{~N}\right)$ is smaller than about $4 \mathrm{MHz}$ in a number of molecules considered in this study, it corresponds to a planar ground-state and a planar equilibrium structure (i.e., a singleminimum inversion potential). If $\left|\chi_{c c}\right|$ is larger than $4 \mathrm{MHz}$, it seems to indicate that the equilibrium structure is nonplanar. The larger the value of $\left|\chi_{c c}\right|$, the more likely that even the ground-state structure is nonplanar. Ground-state quartic centrifugal distortion parameters show a huge effect of the internal rotation of the methyl group in methyl carbamate, but this is of less concern for this study. On the other hand, for example, the $\Delta_{J K}$ centrifugal distortion constant is obviously sensitive to the existence of a plane of symmetry of MC, but it is difficult to draw any safe conclusions by comparing the measured and computed values. Overall, the absence of $c$-type transitions seems to be the most definitive observation supporting the planarity of the ground-state structure of any related compound of interest.

The methyl carbamate molecule was chosen as a model for a behavior that seems characteristic of many molecules containing the peptide linkage. MC has an effectively planar groundstate structure, all atoms except the two out-of-plane methyl hydrogens are in a plane, and a nonplanar equilibrium structure. The equilibrium inversion (pyramidalization) barrier about $\mathrm{N}$ is small, about $50 \mathrm{~cm}^{-1}$, whereas the harmonic frequency corresponding to the inversion motion is about $220 \mathrm{~cm}^{-1}$. The ground-state structure of $\mathrm{MC}$ corresponding to the planar $\mathrm{CONH}$ linkage is supported experimentally by the absence of $c$-type transitions in the rotational spectrum and by a small positive vibrational contribution to the inertial defect. The apparent discrepancy between the nonplanar equilibrium and the planar ground-state structures can be resolved by correcting the groundstate rotational constants by vibrational-rotational interaction constants which leads to values of these rotational constants close to the nonplanar equilibrium structure values. This joint use of high-level theoretical and experimental information is the only route that can be recommended to decide about the equilibrium vs ground-state planarity of molecules containing the $\mathrm{CONH}$ linkage.

It was shown that it is possible to use the frozen-core VQZ MP2 level to estimate the equilibrium $\mathrm{CN}$ and $\mathrm{CO}$ bond lengths. For the $\mathrm{C}-\mathrm{N}$ bond, there is no offset, whereas for the $\mathrm{C}=\mathrm{N}$ bond, there is a small offset of about $-0.002 \AA$. For the CO bond, the picture is a bit more complicated because the offset increases (in absolute value) when the bond length decreases. It is also interesting to note that the $\mathrm{C}-\mathrm{N}$ bond length is the shortest in formamide which happens to be the only planar molecule (Table 15). Furthermore, it appears that the less planar the molecule, the longer the $\mathrm{C}-\mathrm{N}$ bond becomes. However, other factors may be important. For instance, the presence of adjacent multiple bonds $(\mathrm{C} \equiv \mathrm{N}$ in cyanamide) complicates the pattern. It may also be noted that the range of the $\mathrm{N}-\mathrm{H}$ bond length is rather small: it varies from $1.000 \AA$ (for acetamide) to $1.010 \AA$ (for methylamine). Finally, it is also remarkable that the $\mathrm{N}-\mathrm{H}$ bond length is the longest for nonplanar molecules: urea (1.005 $\AA$ ), cyanamide (1.007 $\AA$ ), and methylamine (1.010 A).

The elaborate structural analysis of this study suggests that formamide should not be considered as a general model of the amide linkage and a more complex picture be adapted as typical for molecules containing the CONH linkage. The main characteristics of this emerging picture are the nonplanar equilibrium structure, the exceedingly small barrier to pyramidalization about $\mathrm{N}$, and the possibility of a subsequent planar ground-state structure. Acetamide and methyl carbamate, the latter studied in detail here, seem to be good model compounds exhibiting such features.

Acknowledgment. The work performed in Budapest received support from the Hungarian Scientific Research Fund, OTKA, through Grant T047185. The joint work between Budapest and Lille was partially supported by the BALATON program (08964QF) and partially by the QUASAAR program of the European Commission and the "Laboratoire Européen de Spectroscopie Moléculaire" of the CNRS.

Supporting Information Available: Tables containing a complete list of ab initio structural results obtained during this study, and a brief discussion of how $r_{\mathrm{e}}^{\mathrm{BO}}$ values of the different molecules were derived. This material is available free of charge via the Internet at http://pubs.acs.org.

\section{References and Notes}

(1) (a) Wheland, G. Resonance in Organic Chemistry; Wiley: New York, 1955; p 345. (b) Pauling, L. Nature of the Chemical Bond, 2nd ed.; Cornell University Press: Ithaca, NY, 1960; p 276. 5943.

(2) Wiberg, K.; Laidig, K. E. J. Am. Chem. Soc. 1987, 109, 5935-

(3) Fogarasi, G.; Szalay, P. G. J. Phys. Chem. A 1997, 101, 14001408

(4) Little, G. B.; Gerry, M. C. L. J. Mol. Spectrosc. 1978, 71, 321342.

(5) Rick, S. W.; Cachau, R. E. J. Chem. Phys. 2000, 112, 5230-5241. 
(6) Hirota, E.; Sugisaki, R.; Nielsen, C. J.; Sørensen, G. O. J. Mol. Spectrosc. 1974, 49, 251-267.

(7) Kawashima, Y.; Suenram, R. D.; Hirota, E. J. Mol. Spectrosc. 2003, 219, 105-118. 84.

(8) Marstokk, K.-M.; Møllendal, H. Acta Chem. Scand. 1999, 53, 79-

(9) Bakri, B.; Demaison, J.; Kleiner, I.; Margulès, L.; Møllendal, H.; Petitprez, D.; Wlodarczak, G. J. Mol. Spectrosc. 2002, 215, 312-316.

(10) Császár, A. G. J. Am. Chem. Soc. 1992, 114, 9568-9575.

(11) Császár, A. G. J. Mol. Struct. 1995, 346, 141-152.

(12) Császár, A. G.; Perczel, A. Prog. Biophys. Mol. Biol. 1999, 71, 243-309.

(13) Kasalová, V.; Allen, W. D.; Schaefer, H. F., III; Czinki, E.; Császár, A. G. J. Comp. Chem. 2007, in press.

(14) Szalay, V.; Császár, A. G.; Senent, M. L. J. Chem. Phys. 2002, 117, 6489-6492.

(15) (a) Császár, A. G.; Szalay, V.; Senent, M. L. J. Chem. Phys. 2004, 120, 1203-1207. (b) Allen, W. D.; Bõdi, A.; Szalay, V.; Császár, A. G. J. Chem. Phys. 2006, 124, 224310.

(16) Møller, C.; Plesset, M. S. Phys. Rev. 1934, 46, 618-622. 1918 .

(17) Purvis, G. D., III; Bartlett, R. J. J. Chem. Phys. 1982, 76, 1910-

(18) Raghavachari, K.; Trucks, G. W.; Pople, J. A.; Head-Gordon, M. Chem. Phys. Lett. 1989, 157, 479-483.

(19) Kohn, W.; Sham, L. J. Phys. Rev. A 1965, 140, 1133-1138.

(20) Becke, A. D. J. Chem. Phys. 1993, 98, 5648-5652.

(21) Lee, C. T.; Yang, W. T.; Parr, R. G. Phys. Rev. B 1988, 37, 785789 .

(22) Dunning, T. H., Jr. J. Chem. Phys. 1989, 90, 1007-1023.

(23) Peterson, K. A.; Kendall, R. A.; Dunning, T. H., Jr. J. Chem. Phys. 1993, 99, 1930-1944.

(24) Kendall, R. A.; Dunning, T. H., Jr.; Harrison, R. J. J. Chem. Phys. 1992, 96, 6796-6806.

(25) Frisch, M. J.; Trucks, G. W.; Schlegel, H. B.; Scuseria, G. E.; Robb, M. A.; Cheeseman, J. R.; Montgomery, J. A., Jr.; Vreven, T.; Kudin, K. N.; Burant, J. C.; Millam, J. M.; Iyengar, S. S.; Tomasi, J.; Barone, V.; Mennucci, B.; Cossi, M.; Scalmani, G.; Rega, N.; Petersson, G. A. Nakatsuji, H.; Hada, M.; Ehara, M.; Toyota, K.; Fukuda, R.; Hasegawa, J.; Ishida, M.; Nakajima, T.; Honda, Y.; Kitao, O.; Nakai, H.; Klene, M.; Li, X.; Knox, J. E.; Hratchian, H. P.; Cross, J. B.; Adamo, C.; Jaramillo, J.; Gomperts, R.; Stratmann, R. E.; Yazyev, O.; Austin, A. J.; Cammi, R.; Pomelli, C.; Ochterski, J. W.; Ayala, P. Y.; Morokuma, K.; Voth, G. A.; Salvador, P.; Dannenberg, J. J.; Zakrzewski, V. G.; Dapprich, S.; Daniels, A. D.; Strain, M. C.; Farkas, O.; Malick, D. K.; Rabuck, A. D.; Raghavachari, K.; Foresman, J. B.; Ortiz, J. V.; Cui, Q.; Baboul, A. G. Clifford, S.; Cioslowski, J.; Stefanov, B. B.; Liu, G.; Liashenko, A.; Piskorz, P.; Komaromi, I.; Martin, R. L.; Fox, D. J.; Keith, T.; Al-Laham, M. A.; Peng, C. Y.; Nanayakkara, A.; Challacombe, M.; Gill, P. M. W.; Johnson, B.; Chen, W.; Wong, M. W.; Gonzalez, C.; Pople, J. A. Gaussian 03, revision B.04; Gaussian Inc.: Pittsburgh, PA, 2003.

(26) Császár, A. G.; Allen, W. D. J. Chem. Phys. 1996, 104, 27462748.

(27) Peterson, K. A.; Dunning, T. H., Jr. J. Chem. Phys. 2002, 117, $10548-10560$

(28) Basis sets were obtained from the Extensible Computational Chemistry Environment Basis Set Database, Version 6/19/03, as developed and distributed by the Molecular Science Computing Facility, Environmental and Molecular Sciences Laboratory which is part of the Pacific Northwest Laboratory, P.O. Box 999, Richland, Washington 99352, U.S.A., and funded by the U.S. Department of Energy. The Pacific Northwest Laboratory is a multiprogram laboratory operated by Battelle Memorial Institute for the U.S. Department of Energy under Contract DE-AC06-76.RLO 1830. Contact David Feller or Karen Schuchardt for further information.

(29) Margulès, L.; Demaison, J.; Rudolph, H. D. J. Mol. Struct. 2001, $599,23-30$.

(30) MOLPRO 2000 is a package of ab initio programs written by Werner, H.-J. and Knowles, P. J.; with contributions from Amos, R. D.; Bernhardsson, A.; Berning, A.; Celani, P.; Cooper, D. L.; Deegan, M. J. O.; Dobbyn, A. J.; Eckert, F.; Hampel, C.; Hetzer, G.; Korona, T.; Lindh, R.; Lloyd, A. W.; McNicholas, S. J.; Manby, F. R.; Meyer, W.; Mura, M. E.; Nicklass, A.; Palmieri, P.; Pitzer, R.; Rauhut, G.; Schütz, M.; Stoll, H.; Stone, A. J.; Tarroni, R.; Thorsteinsson, T.

(31) Hampel, C.; Peterson, K. A.; Werner, H.-J. Chem. Phys. Lett. 1992, $190,1-12$ and references therein.

(32) Deegan, M. J. O.; Knowles, P. J. Chem. Phys. Lett. 1994, 227, $321-326$.

(33) (a) Stanton, J. F.; Gauss, J.; Watts, J. D.; Lauderdale, W. J.; Bartlett, R. J. Int. J. Quantum Chem. Symp. 1992, 26, 879-894. (b) See also http:// aces2.de.

(34) Lee, T. J.; Scuseria, G. E. In Quantum Mechanical Electronic Structure Calculations with Chemical Accuracy; Langhoff, S. R., Ed.; Kluwer: Dordrecht, The Netherlands, 1995; pp 47-108.
(35) Helgaker, T.; Gauss, J.; Jørgensen, P.; Olsen, J. J. Chem. Phys. 1997, 106, 6430-6440.

(36) Fogarasi, G.; Zhou, X. F.; Taylor, P. W.; Pulay, P. J. Am. Chem. Soc. 1992, 114, 8191-8201.

(37) Demaison, J.; Cosléou, J.; Bocquet, R.; Lesarri, A. G. J. Mol. Spectrosc. 1994, 167, 400-418.

(38) Demaison, J.; Margulès, L.; Boggs, J. E. Chem. Phys. 2000, 260, 65-81.

(39) Margulès, L.; Demaison, J.; Boggs, J. E. Struct. Chem. 2000, 11, $145-154$.

(40) Margulès, L.; Demaison, J.; Boggs, J. E. J. Mol. Struct. (THEOCHEM) 2000, 500, 245-258.

(41) Lee, T. J.; Taylor, P. R. Int. J. Quant. Chem. Symp. 1989, 23, 199207.

(42) Brown, R. D.; Godfrey, P. D.; Kleibömer, B. J. Mol. Spectrosc. 1987, 124, 34-45.

(43) McNaugthon, D.; Evans, C. J.; Lane, S.; Nielsen, C. J. J. Mol. Spectrosc. 1999, 193, 104-117.

(44) Watson, J. K. G.; Roytburg, A.; Ulrich, W. J. Mol. Spectrosc. 1999, 196, 102-119.

(45) Kisiel, Z. J. Mol. Spectrosc. 2003, 218, 58-63.

(46) Stanton, J. F.; Lopreore, C. L.; Gauss, J. J. Chem. Phys. 1998, 108, 7190-7196.

(47) Allen, W. D.; Császár, A. G. J. Chem. Phys. 1993, 98, 29833015 .

(48) Mills, I. M. In Molecular Spectroscopy: Modern Research; Mathews, C. W., Ed.; Academic Press: New York, 1972; Vol. 1, pp 115140.

(49) Brown, R. D.; Godfrey, P. D.; Kleibömer, B. J. Mol. Spectrosc 1985, 114, 257-273.

(50) Tyler, J. K.; Sheridan, J.; Costain, C. C. J. Mol. Spectrosc. 1972, 43, 248-261.

(51) Kapellos, S. T.; Mavridis, A. J. Mol. Struct. (THEOCHEM) 1993 , $279,151-156$.

(52) Demaison, J.; Margulès, L.; Boggs, J. E. Struct. Chem. 2003, 14 $159-174$.

(53) Ilyushin, V. V.; Alekseev, E. A.; Dyubko, S. F.; Kleiner, I.; Hougen, J. T. J. Mol. Spectrosc. 2004, 227, 115-139.

(54) Yamaguchi, A.; Hagiwara, S.; Odashima, H.; Takagi, K.; Tsunekawa, S. J. Mol. Spectrosc. 2002, 215, 144-154.

(55) Note that the group $C_{s}$ means here the point group to which the equilibrium structure belongs to and can be strictly used to characterize vibration-rotation energy levels when large-amplitude vibrations are absent. Taking into account large amplitude motion requires the use of LonguetHiggins permutation-inversion groups.

(56) Kitano, M.; Kuchitsu, K. Bull. Chem. Soc. Jpn. 1973, 46, 30483051 .

(57) Kydd, R. A.; Dunham, A. R. C. J. Mol. Struct. 1980, 69, 79-88.

(58) Hansen, E. L.; Larsen, N. W.; Nicolaisen, F. M. Chem. Phys. Lett. 1980, 69, 327-331.

(59) Wong, M.; Wiberg, K. B. J. Phys. Chem. 1992, 96, 668-671.

(60) Samdal, S. J. Mol. Struct. 1998, 440, 165-174.

(61) Godfrey, P. D.; Brown, R. D.; Hunter, A. N. J. Mol. Struct. 1997, 413-414, 405-414. 967.

(62) Khanna, R. K.; Moore, M. H. Spectrochim. Acta A 1999, 55, 961-

(63) van Alsenoy, C.; Williams, J. O.; Schäfer, L. J. Mol. Struct. (THEOCHEM) 1981, 76, 179-185.

(64) Remko, M.; Scheiner, S. J. Mol. Struct. (THEOCHEM) 1988, 180, $175-188$.

(65) Kwiatkowski, J. S.; Leszczynski, J. J. Mol. Struct. 1993, 297, 277284.

(66) Marstokk, K.-M.; Møllendal, H.; Samdal, S. J. Mol. Struct. 2000, $524,69-85$.

(67) Flood, E.; Pulay, P.; Boggs, J. E. J. Am. Chem. Soc. 1977, 99, $5570-5574$

(68) Laurie, V. W. J. Chem. Phys. 1958, 28, 704-706.

(69) Belsley, D. A. Conditioning Diagnostics; Wiley: New York, 1991.

(70) Kassi, S.; Petitprez, D.; Wlodarczak, G. J. Mol. Struct. 2000, 517518, 375-386.

(71) Brown, R. D.; Godfrey, P. D.; Storey, J. J. Mol. Spectrosc. 1975 , $58,445-450$.

(72) Xu, L.-H.; Lees, R. M.; Hougen, J. T. J. Chem. Phys. 1999, 110, $3835-3841$.

(73) Curtiss, L. A.; Raghavachari, K.; Redfern, P. C.; Rassolov, V.; Pople, J. A. J. Chem. Phys. 1998, 109, 7764-7776.

(74) Wong, M. W. Chem. Phys. Lett. 1996, 256, 391-399.

(75) Bauschlicher, C. W.; Ricca, A.; Partridge, H.; Langhoff, S. R. In Recent Advances in Density Functional Methods; Chong, D. P., Ed.; World Scientific: Singapore, 1997; pp 165-227.

(76) Allen, W. D.; Császár, A. G.; Horner, D. A. J. Am. Chem. Soc. 1992, 114, 6834-6849.

(77) Rauhut, G.; Pulay, P. J. Phys. Chem. 1995, 99, 3093-3100. 
(78) Carter, J. C.; Devia, J. E. Spectrochim. Acta A 1973, 29, 623632.

(79) Kydd, R. A.; Rauk, A. J. Mol. Struct. 1981, 77, 227-238.

(80) Pople, J. A.; Krishnan, R.; Schlegel, H. B.; DeFrees, D.; Binkley, J. S.; Frisch, M. J.; Whiteside, R. F.; Hout, R. F.; Hehre, W. J. Int. J. Quantum Chem. Symp. 1981, 15, 269-278.

(81) Martin, J. M. L.; El-Yazal, J.; François, J.-P. J. Phys. Chem. 1996 $100,15358-15367$.

(82) Herschbach, D. R. J. Chem. Phys. 1959, 31, 91-108

(83) Császár, A. G.; Fogarasi, G. J. Chem. Phys. 1988, 89, 7646-7648

(84) Kukolich, S. G.; Nelson, A. C. Chem. Phys. Lett. 1971, 11, 383384
(85) Bakri, B.; Demaison, J.; Margulès, L.; Møllendal, H. J. Mol. Spectrosc. 2001, 208, 92-100.

(86) Blukis, U.; Kasai, P. H.; Myers, R. J. J. Chem. Phys. 1963, 38, $2753-2760$.

(87) Priem, D.; Cosléou, J.; Demaison, J.; Merke, I.; Stahl, W.; Jerzembeck, W.; Bürger, H. J. Mol. Spectrosc. 1998, 191, 183-198.

(88) Takagi, K.; Kojima, T. J. Phys. Soc. Jpn. 1971, 30, 1148-1151.

(89) Kreglewski, M. J. Mol. Spectrosc. 1989, 133, 10-21.

(90) Iijima, T.; Jimbo, H.; Taguchi, M. J. Mol. Struct. 1986, 144, 381-

(91) McKean, D. C. Chem. Comm. 1961, 1373.

(92) Demaison, J.; Wlodarczak, G. Struct. Chem. 1994, 5, 57-66. 